\title{
ECONOMIC INTEGRATION, SIMILARITY AND CONVERGENCE IN THE EU AND CEECS TRADE STRUCTURES
}

\author{
Luca De Benedictis* and Lucia Tajoli ${ }^{\dagger}$
}

24 July 2003

\begin{abstract}
In this paper we look at similarity and convergence between the EU and four of the so-called "accession countries" of Central and Eastern Europe in terms of trade patterns. We analyse the trade patterns of the Central and Eastern European countries by comparing them to those of the current members of the EU. In particular, this paper focuses on countries' specialization as suppliers for the EU market.

We evaluate the appropriateness of different classes of similarity indices, using rank correlation index and two distance metrics, the Euclidean index and the Bray-Curtis index.

We examine the evolution of similarity along time - from 1989 to 2000 - considering both self-similarity (how the export structure of a EU member-to-be has changed with respect to the beginning of the transition process) and EU-similarity (if and how the export structure of a EU member-to-be has changed with respect to the EU export structure). Finally, we examine how the process of integration with the EU and its reflection in the increased relevance of processed trade influenced the CEECs' current pattern of specialization.
\end{abstract}

Keywords: EU, CEECs, Transition, Similarity, Distance, Convergence.

JEL Classification: F3, F42

*DIEF - University of Macerata - Via Crescimbeni 20, Macerata 62100, Italy. ++390733258235 . debene@unimc.it

$\dagger^{\dagger}$ Dipartimento di Ingegneria Gestionale, Politecnico di Milano - Via Giuseppe Colombo 40, Milano 20133, Italy. ++390223992752. lucia.tajoli@polimi.it

A preliminary version of this paper was presented at the 6th Conference on Current Trends in Economics, Society for the Advancement of Economic Theory, Rhodes, June 30 - July 6, 2003. The authors wish to thank participants to the International Trade session of the Conference for useful comments and suggestions. Financial support from the EU 5th Framework Program, Project FLOWENLA, $\mathrm{N}^{\circ}$ HPSE-CT2001-00064 and from MIUR, PRIN prot. 2002138555 is gratefully acknowledged. 


\section{NON TECHNICAL SUMMARY}

European integration, which started over 40 years ago, is widely believed to be one of the most remarkably successful examples of regional integration. In spite of periods of slowdown and obstacles, economic integration in Europe has proceeded rather smoothly over the years, and there is a large consensus that benefits have outweighed costs in this process. Integration has also occurred apparently without creating significant adjustment costs for old members or newcomers. An explanation often acknowledged for the ease of European integration in the past is that there was little trade diversion and that the countries involved displayed many similarities. This meant that a large increase in intra-industry trade (IIT) occurred, whose distributional consequences are usually considered more benign than those associated with increased inter-industry trade.

Will it be the same in the new phase of European enlargement to include the Central and Eastern European Countries (CEECs)? The European Commission is closing accession negotiation with Poland, Czech Republic, Hungary, Slovenia, Slovakia, Estonia, Latvia, Lithuania, Malta and Cyprus, and officially declared that all these countries could be ready for joining the European Union (EU) by 2004. This "readiness" comes as a consequence of a long process during which the economies of the candidate countries had to become "functioning market economies" and show "the capacity to cope with competitive pressure and market forces within the Union", as stated by the so-called Copenhagen criteria defining the membership conditions. The conditions for accession to the EU, requiring that applicants reach an economic, political and institutional situation comparable to the one of the EU members, is precisely motivated by the assumption that convergence will ease integration. In this paper we look at this issue by considering a specific manifestation of a "market economy", that is its trade pattern. We analyze the trade patterns of the Central and Eastern European countries applying for membership to the European Union by comparing them to those of the current members of the EU. In particular, this paper focuses on countries' specialization as suppliers for the EU market. The analysis compares the structure of exports directed to the European Union market from EU members and members-to-be.

Since there is neither an obvious measure of similarity, nor an acquainted methodology in terms of the indicator to use in order to compare trade patterns, in the paper we evaluate the appropriateness of different classes of indices. We analyze the similarity in export structure using the (plain and rank) correlation index and two distance metrics, the Euclidean index and the Bray-Curtis index, this latter metric - broadly used in geostatistics and 
in biometrics has never been applied to trade issues.

We examine the evolution of similarity along time - from 1989 to 2000 considering both self-similarity (how the export structure of a EU memberto-be has changed with respect to the beginning of the transition process) and EU-similarity (if and how the export structure of a EU member-to-be has changed with respect to the EU export structure). For all four countries examined, the trade structure changed significantly, especially in comparison to what happened to the EU, that displays a much higher stability of its export structure in the same period. These changes brought Poland and Hungary much closer to the EU, while Romania started to display a little convergence only in recent years, and Bulgaria instead has been diverging.

Finally, we examine how the process of integration with the EU influenced the CEECs' current pattern of specialization. These same countries signed agreements with the EU nearly ten years ago, liberalizing to a large extent their bilateral trade flows, receiving a large amount of foreign direct investments from EU members, and integrating their industries with the Western European ones through different forms of delocalization of production. We tackle this issue emphasizing the relevance of temporary trade flows related to the international fragmentation of production of EU members in the evolution of similarity and in the convergence in specialization, showing how processed trade is relevant in determining the structure of exports of both EU-converging and EU-diverging transition countries.

This analysis of the process of integration and the increasing relevance of processed trade in import-export flows between the CEECs and the EU influenced the level of similarity and convergence in trade patters is pertinent in assessing the impact of the future EU enlargement, which should bring the European integration process to completeness. 


\section{Contents}

1 Introduction. 5

$\begin{array}{lll}2 & \text { The role of convergence in trade patterns } & 7\end{array}$

3 Changes in CEECs' exports pattern $\quad \mathbf{8}$

3.1 The initial re-orientation of trade structures . . . . . . . . . 8

3.2 Our data . . . . . . . . . . . . . . . . . . . 99

3.3 Tukey's boxplots . . . . . . . . . . . . . . . 13

4 Similarity in trade structures $\quad \mathbf{1 5}$

4.1 Distance metrics and similarity matrices . . . . . . . . . . . 15

4.2 Self-similarity: Moving away from 1989's exports structure? . 17

4.3 EU-similarity: CEECs' exports convergence to EU's structure. One fits all? . . . . . . . . . . . . . . . . 19

5 Integration, processed trade, and convergence $\quad 20$

5.1 Mantel's test .................... . . 21

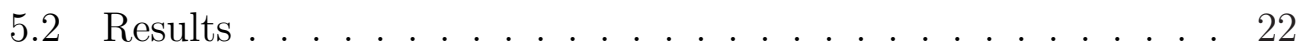

6 Conclusions $\quad 23$ 


\section{Introduction.}

The process of European integration is on the eve of one of the most important events in its nearly half-century-long history, the enlargement to ten new members, eight of which from Central and Eastern Europe. ${ }^{1}$ The European Union $(\mathrm{EU})$ is not new to changes: in spite of periods of slowdown and obstacles, economic integration in Europe has already proceeded through four enlargements, and the scope of policies and aims of its members were ambitiously extended over the years. The general consensus is that the EU is a remarkably successful example of regional integration, where benefits have outweighed costs for all participants. Such outcome was possible also because integration has occurred apparently without creating significant adjustment costs for old members or newcomers.

Will it be the same in the new phase of European enlargement to include the Central and Eastern European countries (CEECs)? The question is pertinent not only because this is the largest enlargement for the EU in terms of number of new members and increase in population, but especially because of the large gap existing between the economic situation of the current and future members. Most of the applicants are countries in transition building up their economic systems and institutions after a long period of central planning and isolation from the rest of the world, and during the past decade they had to deeply re-shape their economies. In these countries, the process of industrial restructuring and institution building were very much influenced by the prospective entrance into the EU (Kaminski, 2001; Nuti, 2001). Negotiations for accession of the CEECs to the EU were guided by the so-called Copenhagen criteria, requiring that candidates reach an economic, political and institutional situation comparable to the one of the EU members before joining the Union. In particular, the candidate countries had to become "functioning market economies" and show "the capacity to cope with the competitive pressure and market forces within the Union" (European Council, 1993). Such requirement is motivated by the assumption that convergence between old and new members will ease the integration process and will minimize the risks of weakening the "common market" conception.

\footnotetext{
${ }^{1}$ The European Council in December 2002 successfully closed the accession negotiations with the Czech Republic, Hungary, Poland, Slovakia, Slovenia, Estonia, Latvia, Lithuania, Malta and Cyprus. All these countries will become members of the EU in May 2004. Bulgaria and Romania are also candidates to EU membership, but for these two countries the date of entrance into the EU has not been established yet. The approach and negotiation process lasted many years: most of these countries signed agreements with the EU liberalizing to a large extent their bilateral trade flows back in the early 1990s, and in the same period they applied for membership to the EU.
} 
In this paper we look closely at one specific aspect of such convergence, that is the evolution of the trade patterns of Central and Eastern European countries applying for membership to the EU, comparing them to those of the current members of the EU. The aim of the paper is threefold: first of all, we discuss how to measure convergence in trade structures to find a reliable indicator of similarity among countries; secondly, we assess whether such convergence was achieved by the CEECs; and finally, we examine how the process of integration with the EU influenced the CEECs' convergence and current pattern of specialization. We tackle this issue emphasizing the relevance of temporary trade flows and trade in intermediate goods related to the international fragmentation of production of EU members in the evolution of similarity and in the convergence in specialization.

The analysis of trade structures is relevant for many reasons: economic integration between the EU and the CEECs started first of all through trade, and liberalization of trade flows already had some time to display its effects. Therefore, trade patterns are a good starting point to observe whether the differences between EU members and the CEECs are narrowing. Furthermore, as long as trade flows attest the comparative advantage of countries, they can provide useful indications on whether these countries can cope with "the competitive pressure and market forces within the Union", and about the future division of labour in the EU. An evaluation of the similarities between the pattern of specialization of the CEECs and the EU is therefore useful to assess the impact of the future enlargement.

Since there is neither an obvious measure of similarity nor an acquainted methodology in terms of the indicator to use in order to compare trade patterns (Clark and van Wincoop, 2000), in the paper we evaluate the appropriateness of different classes of indices. We analyze the similarity in export structure using plain and rank correlation indices - the class of indices more frequently used in the comparison of trade structures (Brülhart, 2000) - and two distance metrics, the Euclidean index and the Bray-Curtis index, this latter metric - broadly used in geostatistics and in biometrics has never been applied to trade issues.

We examine the evolution of similarity along time - from 1989 to 2000 considering both self-similarity (how the export structure of a EU memberto-be has changed with respect to the beginning of the transition process) and EU-similarity (if and how the export structure of a EU member-to-be has changed with respect to the EU export structure).

The analysis of similarity indices shows that for the four countries examined the export structure changed remarkably, and not only in the early phases of transition. The direction of such changes, albeit displaying a different dynamic if using different indices, is generally toward the EU export 
structure for Poland, Hungary and Romania, with different intensities, but not for Bulgaria.

\section{The role of convergence in trade patterns}

The main assumption behind the analysis of convergence in trade patterns presented here is that similarity in production and trade structures among countries will ease the integration process. Depending upon the initial assumptions, according to some theoretical models, countries will trade more between them and obtain higher gains from trade if they are different (in terms of factor endowments in the Heckscher-Ohlin tradition or in terms of technology in Ricardian models), while according to other models (enhancing imperfect competition and intra-industry trade) trade will occur especially among similar countries. In spite of these different approaches, it is generally agreed that adjustment costs are smaller when integration occurs between countries that are relatively alike.

There are also macroeconomic considerations suggesting that when integration goes far beyond trade (like in the case of the EU), convergence in production and trade structure help in smoothing the integration process. The more similar countries are, the more likely they will be exposed to common shocks (Brülhart, 2000) and greater similarity in production structures is likely to increase business cycle correlations (Krugman, 1993; Clark and van Wincoop, 2000; Imbs, 2001). This will mean that common macroeconomic and industrial policies will be more effective the larger is the similarity among country members. Furthermore, the issue of similarity in trade and production structures is very important in the prospective of the CEECs joining the European Monetary Union. To constitute an optimal currency area, countries should be exposed to similar shocks, and their pattern of growth should require similar monetary policies (Babetskin et al., 2002). Therefore, even if this is not required by the Maastricht or Copenhagen criteria, some real convergence also in terms of production structure appears desirable.

Similarity played a positive role in the past phases of European integration. This meant that a large increase in intra-industry trade (IIT) occurred, ${ }^{2}$ whose distributional consequences are usually considered to be more benign

\footnotetext{
${ }^{2}$ Krugman (1981) has a model in which the amount of intra-industry trade between two countries depends on similarities in relative factor endowments, and he shows that more trade of this kind implies fewer redistributive problems for the economies involved. Menon and Dixon (1997) argue too that the adjustment costs associated with trade liberalization depend on the extent of intra-industry trade, and they suggest a measure of changes in trade flows that can be used to assess the extent of adjustment costs.
} 
than those associated with increased inter-industry trade (Neven, 1995). On the other hand, a sufficient degree of closeness was indispensable to define common policies in many areas.

In this case, the change in specialization due to trade was small and the shift of factors of production among industries has also been of minor relevance, generating modest adjustments.

Another reason to believe that similar countries integrate more easily is that they are more likely to lie in the same diversification cone, and this allows at least the theoretical possibility to achieve factor price equalization through trade (Deardorff, 1994). Even if not all the assumptions leading to factor price equalization are maintained, trade can bring about convergence in factor prices. ${ }^{3}$ This possibility is very important in view of the next enlargement. Convergence in factor prices implies that incentives to factor mobility will be reduced. In the European context, this would attenuate concerns about the potential migration flows expected from the CEECs to the EU, one of the main issues under discussion in the enlargement process.

\section{Changes in CEECs' exports pattern}

\subsection{The initial re-orientation of trade structures}

The analysis of the CEECs' trade pattern and volumes originated in the past decade a large body of literature ${ }^{4}$. The observation of a group of countries moving almost at once from a situation of no participation to international market exchanges to openness and integration raised the interest of many international trade economists. Much of the early writings circulating right after the fall of the COMECON system of exchange among these countries emphasized the sharp geographical re-orientation of trade flows and the large trade potential existing between the CEECs and the rest of Europe (Wang and Winters, 1994). Those changes were indeed attained: nowadays nearly two thirds of the CEECs trade takes place with members of the EU and volumes of trade increased at a fast rate, so that the CEECs are today the second trade partner of the EU after the U.S.

More uncertainty characterized the predictions of the CEECs' pattern of specialization. In the early phases of transition it seemed evident that it was

\footnotetext{
${ }^{3}$ Indeed, the CEECs experienced a rapid increase in their absolute and relative wages during the 1990s. In the same years, the importance of the EU increased as a trade partner.

${ }^{4}$ For an extensive and recent report on the evolution of industrial and trade specialization in the CEECs see Landesmann (2003).
} 
difficult to infer the CEECs' comparative advantages from the actual trade flows, as the turbulence of the economy at the time was too strong. The comparative advantage of the CEECs could be deduced from their factor endowments, but a correct assessment of these endowments was not easy, as the capital stock of the CEECs was very obsolete, and the actual productivity of the labour force was difficult to measure. Still, most studies agreed that the CEECs' factor endowment was different from the one of countries with similar income levels in that they were much more endowed with human capital and skilled labour (Halpern, 1995).

This endowment was not fully reflected in their trade flows. ${ }^{5}$ By the mid1990s the CEECs appeared specialized in labour-intensive industries and in resource-intensive sectors (Landesmann, 1996; Freudenberg and Lemoine, 1999). But even if by this time most countries had achieved a good degree of macroeconomic stabilization, market functioning was not fully achieved, and their related pattern of trade did not look established yet. At least two observations hinted to changes to be expected. Since the beginning of transition with the process of privatization of the domestic industries, the CEECs were host of a large foreign direct investment inflow. Furthermore, delocalization of production phases from EU firms to the CEECs through outward processing trade affected these countries trade patterns (Baldone et al., 2001, 2002; Kaminski, 2001). Possibly also as a result of these phenomena, the share of intra-industry trade in the CEECs' trade with the EU was higher than what is normally observed for countries with similar income gaps (Atutupane et al., 1997).

From those early analyses of the CEECs' specialization some worries arose about an increase in competition for the EU members with lower labor costs and specialized in traditional industries (Neven, 1995). But the evolution of the CEECs specialization indicates that those worries were rarely justified. In what follows we show that the CEECs specialization changed remarkably and not necessarily in the expected direction.

\subsection{Our data}

Our analysis focuses on the changes occurred in the exports of Poland, Hungary, Romania and Bulgaria towards EU 15 member States, between 1989 and 2000. We consider both total exports, that include temporary EU exports and re-imports of goods temporarily exported, and final exports at a 2 digits sectoral level of the Combined Nomenclature, that includes the 97 sectors, listed in figure 2. The flows considered are in value terms (thousands

\footnotetext{
${ }^{5}$ For a discussion of this point see Tajoli (1998).
} 
of euros) and come from the Comext Eurostat Database, containing custom trade data collected by EU national statistical institutes. ${ }^{6}$

[Figure 1 about here]

In figure 1 we summarize - from top-left to bottom-right panel - the dynamics of Poland, Hungary, Romania, and Bulgaria total and final exports towards the EU's 15 members, taken as an aggregate. Total exports are represented by the vertical lines surmounted by the crossed squares, while the dotted line correspond to the evolution of final exports. In all cases the exports flows are measured relative to 1992 value of national exports towards the EU. ${ }^{7}$

Figure 1 shows eloquently that each of the four export pattern is a case on its own. In the case of Poland, from 1989 to 2000, the value of total exports flows jumped from a little bit more than 0.5 to a triple value relative to 1992. The positively sloped path shows a discontinuity in 1995-1996, but is nonetheless fairly stable. An estimate of the dynamics of total exports towards EU can be easily obtained through a simple linear regression of total exports on a linear time trend. Table 2 shows the estimated coefficients of the time trend, ${ }^{8}$ the significance and the fit of the regressions in the four cases under scrutiny. The first estimates are for Poland: the trend coefficient

\footnotetext{
${ }^{6}$ In the original coding of the Comext Eurostat Database, (1) is normal or final trade flow: mainly goods exported definitively and released into free circulation, either directly or via a customs warehouse. (3) is the trade flow which has undergone outward processing ('tariff' or 'textiles' variant); outward processing makes it possible to export goods temporarily for processing and to import the compensating products with a full or partial exemption from duties and levies. The 'textiles' variant (7), introduced in 1995, concerns only certain textile products or clothing, whereas the 'tariff' alternative is applicable to all other products. (5) and (6) is the movement of goods for inward processing, including imports for inward processing and exports which have undergone inward processing (according to the suspension and the drawback system). Inward processing makes it possible to import goods temporarily so that they can be processed (assembled, transformed, repaired) and the resulting products exported, while benefiting from an exemption from duties, levies and/or checks carried out under the trade policy normally applicable to imported goods. (4) is Total imports, and includes the sum of (1), (3), (5), (6), and (7). Inward and outward processing procedures are independent of the nature of the transaction concerned (purchase/sale, processing under-contract, etc.). In fact, part of the flow of goods for processing, in the economic sense of the term, is included under normal imports and exports.

${ }^{7}$ The choice of the base year is irrelevant for the shape of the four series in figure 1 . The choice is therefore only suggestive: 1992 is significant year in terms of trade reorientation as the former USSR no longer exists.

${ }^{8}$ The estimated intercepts are not included in table 2 since were in all cases non significant.
} 
is positive and highly significant - indicating an annual increase in Polish exports to the EU of $22 \%$ - and the adjusted R-squared statistic is 0.9383 .

Table 1: Total Exports regressions on a time trend.

\begin{tabular}{lrrrrr}
\hline \hline & Estimate & Std. Error & $\mathrm{t}$ value & $\operatorname{Pr}(>|\mathrm{t}|)$ & Adjusted- $R^{2}$ \\
\hline $\begin{array}{l}\text { (Poland) } \\
\text { time trend }\end{array}$ & 0.2241 & 0.0173 & 12.98 & 0.0000 & 0.9383 \\
\hline $\begin{array}{l}\text { (Hungary) } \\
\text { time trend }\end{array}$ & 0.4186 & 0.0492 & 8.50 & 0.0000 & 0.8664 \\
\hline $\begin{array}{l}\text { (Romania) } \\
\text { time trend }\end{array}$ & 0.3541 & 0.0550 & 6.44 & 0.0001 & 0.7864 \\
\hline $\begin{array}{l}\text { (Bulgaria) } \\
\text { time trend }\end{array}$ & 0.2403 & 0.0176 & 13.68 & 0.0000 & 0.9442 \\
\hline
\end{tabular}

The case of Hungary is even more remarkable, the value of total exports more than quintupled from 1992 to 2000. The path was almost flat until 1993, but from 1994 onward the trend becomes positively sloped. The results of the linear regression of total exports on a linear time trend indicate an highly significant average increase in Hungarian exports to the EU of $42 \%$, but an adjusted R-squared statistic of 0.8664 is a sign that the linear functional form is probably not the most appropriate choice.

The bottom-left panel of figure 1 shows that the value of total Romanian exports to the EU followed a J-shaped path. It decreased from 1989 to 1992 and increased the following years, reaching at the edge of the period considered a level five times higher than in 1992 . The 0.7864 adjusted Rsquare indicates that the linear time trend is partially misrepresenting the true dynamics of Romanian exports. The positive coefficient of the regression is still highly significant and shows an annual increase of Romanian exports of $34 \%$.

The 0.9442 adjusted R-square square resulting from estimates for Bulgaria indicates that the true dynamics of Bulgarian total exports is well represented by a linear time trend, in spite of 1996's drop. The coefficient of the regression is positive and highly significant and shows an annual increase of Bulgarian exports of $24 \%$.

Considering separately exports of final goods and re-exports after processing, more differences emerge among countries. Polish final exports follow a path that is very similar to the one of total exports, and the same is true for Hungary. Re-export flows were almost irrelevant in 1989 and reached a 
maximum relevance in 1996, slowly decreasing until $2000 .{ }^{9}$ Instead, the role of processed trade in Romania is and remains substantial along the second half of the 1990s, as shown in figure 1. In Bulgaria processed trade becomes gradually substantial along the second half of the 1990s, as shown in the bottom-right panel of the same figure. For all four countries, the estimated coefficients of a time trend over final exports only are smaller than the coefficients for total trade, indicating that final trade alone grew at a slower pace than trade inclusive of processing traffic. The difference in the two coefficients for each country is statistically significant in all cases, and it is quite large for Romania and Bulgaria.

The changes occurred along the 1990s to CEECS' total exports to the EU are the result of complex sectoral dynamics with common elements and peculiarities that deserve some inspection.

[Figure 2 about here]

Figure 2 presents the pattern of exports toward the EU market of Poland, Hungary, Romania and Bulgaria, comparing shares of exports in 97 sectors in the year 1989 and in the year 2000. For all four countries, the export shares appear fairly uniformly distributed among sectors, most of which contribute to total exports with a small share, below $0.5 \%$, and with at most one sector with a share over 10\%. Back in 1989, only a handful of sectors were comparatively more important for all the countries examined: these are fuels, iron, and apparel. Poland, Hungary, and to some extent Bulgaria displayed a specialization in machinery and electrical machinery as well, and Poland and Romania in the furniture sector. Autovehicles' export in Poland were moderately relevant already back in 1989. All countries exported agricultural products to the EU. The share of some of these sectors remained relevant along the transition, while some other sectors dramatically reduced their share in total exports.

In the year 2000, as shown in the picture, the export share remained stable in nearly half of the sectors, and visible changes appear only in few sectors, that seem to drive most of the observed modification in the export structure. The concentration of change in a few industries is a common feature to all countries, but the affected industries and also the direction of

\footnotetext{
${ }^{9} \mathrm{~A}$ large part of the decrease in the flows of processed re-exports is due to statistical reasons. In fact, after 1996, when trade in most sectors between the EU and the CEECs was liberalized, the EU firms processing goods in the CEECs did not bother anymore to register their exports as temporary, not receiving after that year an advantage in terms of waived duties. Therefore after 1996 much of the processing trade is not statistically recorded and it adds up to the normal trade flows.
} 
change are different between countries. For instance, the agricultural shares and machinery and electrical machinery industry's shares over total exports has changed significantly in all four countries in the past decade, but while the share of machinery in Hungarian and Polish exports toward the EU doubled (or more), the same share actually declined for Bulgaria. The share of apparel exports - another relevant sector in terms of changes - declined in Poland and in Hungary, while it increased in Romania and in Bulgaria. The share of exports in auto vehicles and parts of them increased dramatically in Poland and Hungary, but it remained negligible in Romania and Bulgaria. Overall, even this first visual image conveys the impression that the CEECs' export structure changed far more that of the EU, and that these changes were fairly selective.

Some relevant changes depicted in figure 2 have a strong connection to the development of temporary trade flows related to the international fragmentation of production of EU members. In figure 3 we show for the same group of countries each sector's share over exports of processed goods.

[Figure 3 about here]

Here the changes in shares over the observation period are even more localized, as processing trade does not interest many sectors. Between 1989 and 2000 the flow of processed trade vanished in some sectors, such plastics, glues and organic chemicals in Poland, aluminum, plastics and organic chemicals in Hungary. The case of furniture and aluminum in Romania is even more dramatic, as is the case of organic chemicals, fuels and vegetable preparations in Bulgaria.

In the year 2000, processing trade is concentrated in the apparel sector (both knitted and unknitted), especially in Romania and in Bulgaria, and to a lesser extent in Poland and Hungary. Relevant shares appear also in the footwear industry, in machinery and electrical machinery, especially in the Hungarian case. Interestingly, the industries more affected by processing trade are the same in which relevant movements appeared in figure 2.

\subsection{Tukey's boxplots}

A useful tool for distilling and summarizing the information contained in figure 2, allowing for a broader analysis of the changes occurring along the years, is Tukey's boxplot. The horizontal segment that divides each box contained in the four panels of figure 4 is the the median of sectoral total exports shares' distribution, for every year considered, and indicates the location of the distribution. The upper and lower ends of the box are the upper and the 
lower quartile, and the vertical size of the box is therefore the interquartile range and is a measure of the spread of the distribution. If the interquartile range is small the distribution is highly concentrated around the median; if the interquartile range is large the distribution is less concentrated and the middle sectoral shares spread out far from the median. The relative distances of the upper and the lower quartile from the median indicate the shape of the distribution. If one distance is much bigger than the other, the distribution is skewed. The dashed whiskers encode the adjacent values; the upper adjacent value - identified by the the horizontal spike - is the largest observation that is less than or equal to the upper quartile plus 5 times the interquartile range; the lower adjacent value - not perceivable in figure 4 - is the smallest observation that is greater than or equal to the lower quartile minus 5 times the interquartile range. The observations outside the adjacent values are plotted individually and provide information of the presence of outliers and on the characteristics of the tails of the distribution.

[Figure 4 about here]

The existence of different characteristics in the trade patterns of the four CEECs examined is confirmed by the observation of figure 4. In all countries the distribution tends to become more concentrated over time, as shown by the reduction in the vertical size of the boxes. At the same time, the relevance of the outliers increased over time. For Poland, the median share of sectors' export is stable over time, and quite small, but there is a relevant number of industries with high shares of exports that tend to stretch the right tail of the distribution after 1995. In 2000 in Poland there are six sectors out of 97 accounting for nearly half of total exports. Hungary presents a similar situation, with an extension of the right tail of the distribution over time. In Hungary, five sectors stand out as outliers in 2000, and one single sector the machinery sector - is contributing for nearly $30 \%$ of total exports. The outstanding relevance of a few industries in Polish and Hungarian exports and the growing weight of such outliers seems to indicate that for these two countries the observed movement in their pattern of trade is driven by changes occurred in a specific group of sectors.

In the case of Romania, the role of outliers is reduced over time until 1997, but it increases again in the last years. In Romania, in 1989 one industry (fuels) was accountable for more than $40 \%$ of the exports of this country toward the EU, while in the year 2000 the first three sectors - apparel, footwear, and electrical machinery - made up a similar share. Bulgaria displays the least dispersed distribution of exports over sectors, and it shows an increase in concentration around the median, with the smallest number of outliers. 


\section{Similarity in trade structures}

The visual inspection of figures 2 and 4 gives the impression of relevant changes in the sectoral composition of export structure of Poland, Hungary, Romania, and Bulgaria. On the contrary, the EU seems quite persistent in its export structure. In the next sections we will quantify mobility and persistence with the help of similarity matrices. We will calculate self-similarity matrices in order to measure the distance of each one of the members-tobe to the beginning of the transition process. More over, we will calculate EU-similarity matrices measuring the distance between each member-to-be export structure and the one of the EU as a whole.

\subsection{Distance metrics and similarity matrices}

The traditional measure of the degree of association between two variables is Pearson's coefficient of correlation, which captures the strength of the linear association between the two variables taking the mean as the positional index of the two distributions. Since we have shown that the distribution of CEECs exports to the EU is markedly skewed to the right (even after the eventual log-trasformation of the data), so that the mean overestimates the location of the distribution, the coefficient of correlation is not the most appropriate index to use in measuring the similarity of CEECs sectoral exports structure to the one of the EU.

In order to bypass the problem posed by the comparison of asymmetric distributions, we use a correlation coefficient based on ranks. Spearman's $\rho$ is defined as follows:

$$
\rho_{j k}=1-\frac{6 \sum_{i}\left(r_{i j}-r_{i k}\right)^{2}}{N\left(N^{2}-1\right)}
$$

where $j$ and $k$ are two countries (i.e. Poland and the EU), $i$ is a specific sector, and $N$ is the total number of sectors. $r_{i j}$ is the rank assigned to sector $i$ in country $j$ in a specific year $t \in[1989,2000]$.

We also use $\rho$ rank correlation to calculate autocorrelation matrices for each country, measuring the rank correlation between sectoral exports of the same country given a time lag. In this case $j \neq k$ in terms of year considered, and the $N \times N$ autocorrelation matrix contains the $N^{2}$ couples of rank correlations (but only $N \times(N-1) / 2$ pieces of information) between two specific years $t$ s.

A different and preferable alternative to the use of the rank correlation 
is to measure similarity in terms of distance. ${ }^{10}$ This is why we also use two among the many measures of distance widely used in geostatistics and in biostatistics (Legendre and Legendre, 1998).

All metrics used as a measure of distance must share the same properties, so that we can say that an index $d$ is a metric if:

1. $j=k$, then $d_{j k}=0$

2. $j \neq k$, then $d_{j k}>0$

3. $d_{j k}=d_{k j}$

4. $d_{j w}+d_{w k} \geq d_{j k}$

where property (1) states that the minimum distance should be 0; property (2) says that distance should be a positive real number; property (3) assumes that symmetry is respected; and property (4) states triangular inequality (not respected in cases of semi-metrics).

Among the many candidates for which the above properties are respected, the most common metric measure is the Euclidean distance. It is computed applying Pythagora's formula to country-points positioned in a Ndimensional space called a metric or Euclidean space. The Euclidean distance between two countries $j$ and $k$ identified by $N$ sectors is:

$$
d_{j k}=\sqrt{\sum_{i}\left(x_{i j}-x_{i k}\right)^{2}} .
$$

However, the Euclidean distance, used as a measure of similarity ${ }^{11}$ among countries (EU-similarity) or the same country in different points in time (self-similarity) - on the basis of sectors relative weight, may lead to the double-zeros paradox of two countries without any sectors in common being at a smaller distance than another pair of countries characterized by the same structure of sectoral exports.

In general, double-zeros lead to reduction in distances. In our case the number of sectors with zero value is limited but not irrelevant so we doublecheck the results of equation 2 in terms of self-similarity and EU-similarity using a second metric based on the Manhattan distance:

\footnotetext{
${ }^{10}$ The rank correlation under emphasizes by construction the role of the mean, which is precisely fine given the skewness of the data. This choice is however costly, since the rank correlation gives on purpose no relevance to the sector's relative weight, implying in our case an excessive information loss.

${ }^{11} \mathrm{It}$ is worthwhile noticing that since dissimilarity (distance) is equivalent to the additive inverse of similarity $(d=1-s)$, using similarity (or closeness) instead of dissimilarity has no qualitative effect on the analysis: it merely changes the sign of the coefficients.
} 


$$
d_{j k}=\sum_{i}\left|x_{i j}-x_{i k}\right|
$$

The Manhattan metric, city-block metric, or taxicab metric all refer to the same distance measure. It refers to the fact, that for two sectors, the distance between two countries (or the same country in different years) is the distance on the abscissa plus the distance on the ordinate (much like the orthogonal distances traveled by taxicabs in large towns, such New York).

In spite of its use in trade empirics (Krugman, 1991; Clark and van Wincoop, 2000; Imbs, 2001), the Manhattan metric presents however the same problem with double zeros as the Euclidean distance does. So we normalized the Manhattan distance according to the Bray-Curtis formula:

$$
d_{j k}=\frac{\sum_{i}\left|x_{i j}-x_{i k}\right|}{\sum_{i}\left(x_{i j}+x_{i k}\right)} .
$$

The Bray-Curtis metric is not subject to the double-zeros paradox, it lessen the effect of the largest differences, and is appropriate in presence of skewed distributions. Therefore it has been selected as the preferred semimetric.

\subsection{Self-similarity: Moving away from 1989's exports structure?}

By looking at figures 5 through 8, describing the similarity of the CEECs export structure along time to their initial exports using the correlation and distance metrics presented in the previous section, ${ }^{12}$ it is possible to see that many important changes occurred in the pattern of total exports of the CEECs toward the EU market in the past decade. A large number of such changes took place much after the starting phases of transition. In Poland, the rank correlation $\rho$ declines until 1992 to stabilize somewhat after that year, indicating that the ranking of exporting sectors did not change much in the second half of the 1990s, but the fall of the Pearson 's correlation coefficient after 1995 shows that export shares kept moving also in the most recent years. In terms of this index, the Polish trade structure of 2000 is less similar to the one of 1995 that this last was to the one of 1990. The distance indices present a similar pattern, indicating that Poland kept moving away from its initial specialization, and there is a remarkable distance also between the current trade pattern and the one of 1995.

\footnotetext{
${ }^{12}$ The tables for all the indices reported in the figures appear in the autocorrelation tables annex and are available upon request.
} 
[Figures 5 through 8 about here]

The change in the Hungarian pattern of trade is even sharper, even if the ranking of exporting sectors here too seems to partially stabilize after 1993. By comparing figure 7 to figure 10, showing the dynamics of the EU trade pattern, one can appreciate the extent of the changes that affected the Hungarian exports. While the autocorrelation for the EU is never lower than 0.96, and the distance indices reach at most 0.06 and 0.12 respectively, for Hungary the Pearson's correlation between exports in the year 1989 and 2000 is only about 0.5 and the distance measures arrive to 0.33 and 0.53 , much higher than also in the Polish case.

Both for Hungary and Poland, the indices show that in the early years of economic transition - between 1989 and 1993 - most of the exporting sectors at the top ranks in 2000 appeared to be gradually relevant. After 1993, with some temporarily reversals, the process of change continued to increase the distance from the original trade pattern.

The transformation is quite different in the case of Romania and Bulgaria. Over the entire time span, Romania changes more than Hungary and Poland in terms of all indices, but most of the change is concentrated in the early years and takes place before 1992. After this initial big jump, Romanian exports show a modest dynamic. The country appears locked in the specialization reached in the early 1990. Something similar occurs to Bulgaria, which has changed especially at the beginning of transition and shows a period of stability in the mid-1990, while some movement starts to appear again in the last few years.

Summing up, at the end of the 1990s, the overall picture of the CEECs specialization looks remarkably different from just five years earlier, but these changes are far from being uniform across countries. As the transition process went on, substantial diversity emerged among the CEECs, who display different dynamics of overall changes, and different sectoral movements, as discussed in section 3.2. ${ }^{13}$

Possibly, given that much of the change is concentrated in a few industries, the dynamics of specialization could depend on which are the sectors driving the change. ${ }^{14}$ While Romanian and Bulgarian exports are concentrated first of all in traditional, labour-intensive industries (such as textiles, apparel and footwear), Poland's and Hungary's exports grew in industries such as

\footnotetext{
${ }^{13}$ The tendency toward diverging specializations among the CEECs is pointed out also in other studies. See for example Chiarlone (2002) and Landesmann and Stehrer (2002).

${ }^{14}$ Redding (2001) suggests that over medium time horizons (five years), changes that are specific to individual industries explain most of the observed mobility in the patterns of specialization of the OECD countries he examines.
} 
autovehicles and machinery (see figure 3), in spite of the very large initial gap with the EU members in these sectors. In this catching-up process, foreign capital and technological cooperation with EU firms played an important role.

\subsection{EU-similarity: CEECs' exports convergence to EU's structure. One fits all?}

In this section we examine whether the observed change in the CEECs export structures brought these countries closer to the EU specialization. Here again we prefer not to relay on a single similarity metric, but we compare different indices. This comparison is presented in figures 10 through 13 .

[Figures 10 through 13 about here]

In the case of Poland, all indices show convergence toward the EU, especially after 1994, as possibly speeding up in the last few years. More difficult to interpret is the case of Hungary. In terms of correlation, Hungary approaches the EU and gets even closer than Poland. But if we look at the distance indices, after a period of fast reduction in the distance from the EU, from 1995 Hungary seems to diverge again. Through careful examination of the data, one can see that this occurs because Hungary, in its specialization, goes "beyond convergence". In fact, its main sectors of specialization (machinery and electrical machinery) are the same as for the EU and the general structure of specialization is in line with the EU, as confirmed by the high correlation. But the weight of these important sectors is much higher than for the EU. The Euclidean and Bray-Curtis distance metrics pick up this type of differences and indicate this strong specialization as an increase in distance. The figure for Romania is quite unstable, and it is difficult to see a tendency for the entire time span. But in the last three years Romania as well shows some convergence toward the EU export structure. The tendency for Bulgaria is instead unexpected. This country's export structure has been diverging from the one of the EU, and this tendency appears quite clearly from all indices. Even in the last period there are no signs of a reversal in this trend.

A summary of the dynamics of the CEECs' specialization and their convergence toward the EU export structure is presented in figures 14 and 15, measuring on the horizontal axis respectively the yearly correlation or the similarity of each country's export structure with the EU, and on the vertical axis each country autocorrelation or self-similarity, with respect to its own initial export structure. Vertical movements show the extent of the changes 
in a country export structure, and rightward horizontal movements indicate convergence toward the EU.

[Figures 14 and 15 about here]

Both figures show that the evolution of the candidates is remarkable and quite differentiated. As expected, the CEECs changed their export structure much more dramatically that the EU in the same period. But Hungarian and Polish changes from one year to the next are continuous throughout the decade, while Romania and Bulgaria show large jumps initially and smaller changes in the more recent past. In terms of similarity to the EU, we have a somewhat parallel behavior for Poland and Hungary, moving away from the initial specialization toward the EU. Romania started to converge toward the EU only in the last few years and to a very small extent, and Bulgaria, moving leftward, displays a clear divergence, in spite of starting off as the most similar (or next-to-most similar, depending on the metrics) country to the EU. This pattern shows very little path dependence: the CEECs appearing closer to the EU export structure are not the same at the beginning and at the end of the observation period.

It is also interesting to compare the different indications given by the metrics used. Even if the two pictures display a similar behaviour, the ranking of the four countries is not the same either in terms of self-similarity or similarity to the EU. Looking at figure 14 (using the correlation metric) the country that changed the most its initial trade structure appears to be Romania, while in figure 15 (using the Bray-Curtis metric) is Hungary. Both metrics indicate that Poland has undergone fewer changes from the initial structure than other countries. Interestingly, Poland is considered to be the country that was fastest in stabilizing its macroeconomic fundamentals, but most observers agree on the fact that in microeconomic terms Poland still has a long way to go. Anyway, In the year 2000, Poland seems to have the most similar structure to the EU, but only according to the Bray-Curtis metric. Hungary is instead the country displaying the highest correlation to the EU trade structure.

\section{Integration, processed trade, and conver- gence}

Our next step is to test if the dynamics of sectoral distribution of total exports of Poland, Hungary, Romania, and Bulgaria to the EU, and if EUsimilarity is related to the role acquired by processed trade in the 1990s. 
But this task is confounded by two fundamental issues. First, final trade and processed trade are intercorrelated among themselves, and so it may be difficult to ascribe causal mechanism even if it can be shown that the convergence/divergence with respect to the European benchmark is correlated with countries' sectoral export distribution. Secondly, trade variables are highly persistent, and so their influence is likely to be expressed only at particular scales of reference. Furthermore, the likelihood that the sectors itself may exhibit high autocorrelation in its distribution is not a extreme event, due vertical and horizontal linkages.

In conventional statistical analyses, the former problem is addressed via multivariate methods that allow one to attend the correlations among predictor variables; partial regression is a familiar solution to this problem. But conventional parametric approaches are confounded by the second issue, namely that autocorrelation in the variables violates the assumptions of parametric analysis.

\subsection{Mantel's test}

Mantel's test (Legendre and Legendre, 1998) is an nonparametric approach that overcomes some of the problems inherent in explaining the relationships between total exports and processed trade. Mantel's test is a regression in which the variables are themselves distance or dissimilarity matrices summarizing pairwise similarities among time periods. For example, instead of "sector share $x_{i}$ in year $t$ " the dependent variable is the "similarity in share of sector $x_{i}$ in year $t$ and $t+1$." Likewise, the predictor variable might be "similarity in processed trade shares" between time periods instead of "processed trade share" for a single period.

One advantage of Mantel's test is that, because it proceeds from a distance or a similarity matrix, it can be applied to different kinds of variables (categorical, rank, or interval-scale data) and all that matters is that an appropriate distance metric be employed, such as one we used previously. The Mantel statistic can be described as the evaluation of the significance of a matrix correlation between two dissimilarity matrices. Since the significance cannot be directly assessed, because there are $N(N-1) / 2$ entries for just $N$ observations, the test uses permutations of $N$ rows and columns of one dissimilarity matrix. The statistic can be evaluated either as a moment correlation or as a rank correlation. ${ }^{15}$

Because the elements of a distance matrix are not independent, Mantel's

\footnotetext{
${ }^{15} \mathrm{An}$ alternative to the use of correlation coefficients is referring to the original Mantel's statistic, which is based on a simple cross-product term:
} 
test of significance is evaluated via permutation procedures. In this, the rows and columns of one of the two distance matrices are randomly rearranged. Mantel statistics are recomputed for these permuted matrices, and the distribution of values for the statistic is generated via an iterative procedure. ${ }^{16}$

\section{$5.2 \quad$ Results}

We applied a Mantel's test to each one of the four countries considered in the analysis, using distance matrices for total exports shares and for processed export shares. The operative question is, "Do changes in self-similarity in processed trade tend to match changes in total export self-similarity?"

We used as alternative metric correlation matrices, Euclidean distance matrices and Bray-Curtis matrices evaluated either as a Pearson's correlation or as a Spearman's rank correlation, iterating the procedure of column-row permutation 1000 times.

In all cases, with notable differences, the operative question passed the nonparametric test, meaning that changes in total exports occurred along with the changes in processed trade. This suggest that processed trade is crucial in explaining changes in the overall structure of exports of transition countries. This is true not only for Poland and Hungary, whose trade structures are getting more similar to the EU, but also in the case of Romania (no convergence toward the EU export structure) and even in the case of Bulgaria (divergence from the EU export structure). Apparently, the phenomenon of delocalization of production witnessed by the extent of processed trade, can enhance complementarities among countries within the same industry (like in the case of similar export structures) as well as complementing different export structures through a market division of labour.

$$
m=\sum_{i}^{T} \sum_{\iota}^{T} d_{i t}^{x} d_{\iota t}^{o} .
$$

where in our case $d^{x}$ and $d^{o}$ would have been variables ( $d^{x}$ is total export share distance and $o$ is processed trade share distance) measured at time $i$ and $\iota$ and $T$ is the number of elements in the distance matrices $(T=t(t-1) / 2$ for $t$ time periods). Since we use export shares, this standardization allows one to rescale the statistic to the range of a conventional correlation coefficient bounded on [-1,1].

${ }^{16}$ The number of iterations varies in accordance to the significance of the test: 1000 for $\alpha=0.05,5000$ for $\alpha=0.01,10,000$ for greater precision (Legendre and Legendre, 1998). Moreover, the Mantel's test is based on linear correlation and nonlinear relationships between variables may be degraded or lost. Moreover, the test of time dependence is averaged over all time periods and so the test cannot discover changes in the pattern of correlation at different point in time. 
Table 2: Mantel's test results.

\begin{tabular}{lcccc}
\hline \hline & Spearman correlation & \multicolumn{3}{c}{ Pearson correlation } \\
\hline Poland & Bray-Curtis & Euclidean & Bray-Curtis & Euclidean \\
& 0.908 & 0.7843 & 0.8971 & 0.772 \\
Hungary & $(0.383)$ & $(0.351)$ & $(0.375)$ & $(0.367)$ \\
& 0.9374 & 0.9398 & 0.9405 & 0.9333 \\
Romania & $(0.382)$ & $(0.357)$ & $(0.383)$ & $(0.432)$ \\
& 0.9303 & 0.8787 & 0.9407 & 0.9389 \\
& $(0.542)$ & $(0.549)$ & $(0.581)$ & $(0.626)$ \\
\hline Bulgaria & 0.8556 & 0.6824 & 0.8815 & 0.7137 \\
& $(0.502)$ & $(0.401)$ & $(0.470)$ & $(0.385)$ \\
\hline
\end{tabular}

Note: Empirical 99\% upper confidence limits of $m$ in parenthesis.

\section{Conclusions}

The analysis of the dynamics of the CEECs specialization and their convergence toward the EU export structure shows that the process of re-shaping the pattern of trade has been long, and it is still continuing. Another aspect which is emerging is that the evolution of different candidates is dissimilar. While we have a converging behavior for Poland and Hungary, moving away from the initial specialization toward the EU, Romania started to converge toward the EU only in the last few years and to a very small extent, and Bulgaria displays a diverging trend. It seems therefore that two different tendencies emerge, creating a "convergence club" and a group of countries that so far are not showing a clear and definitive sign of convergence towards the EU trade structure.

This kind of result emerged also in other different works, but it is interesting that our comparison, without making any assumption on the countries' structural characteristics, indicates the countries displaying less convergence are also the countries that were found not ready for accession, using quite different criteria. This result gives support to the view of the evolution of trade patterns being in line with the evolution of other economic indicators.

The issue of what caused the change in trade pattern is at this stage still open. But our evidence shows that CEECs total exports toward the EU are influenced by other forms of integration, such as fragmentation of production. Processing trade can foster both convergence or divergence in trade structures, according to the characteristics of the industries involved, 
and whether these are shrinking in the EU and being moved to other locations or expanding.

Different indications on the speed and the degree of similarity in trade patterns emerge using different indices, rising a methodological issue on how to measure similarity. Our contribution shows that when changes occur in sectors characterized by large export shares the traditional correlation analysis can lead to misleading conclusions, and some alternative metric - such the Bray-Curtis distance - must be used. If EU-similarity in trade structure should be a criterion for readiness of a country to join an integrated area, or an indicator of adjustments expected, how to measure similarity and convergence is a point that needs to be explored further. 


\section{References}

Atutupane C., Djankov S. and Hoekman (1997) Determinants of intra-idustry trade between East and West Europe, CEPR Discussion Paper no.1721.

Babetskin J., Boone L. and Maurel M. (2002) Exchange rate regimes and supply shocks asymmetry: the case of the accession countries, CEPR Discussion Paper n. 3408.

Baldone S., Sdogati F. and L.Tajoli (2001) Patterns and Determinants of International Fragmentation of Production. Evidence from Outward Processing Trade between the EU and the Countries of Central-Eastern Europe, Weltwirtshaftliches Archiv, 80-104.

Baldone S., Sdogati F. and L.Tajoli (2002) International fragmentation of production, trade flows and growth, presented at the 53rd IAES Conference, Paris.

Brülhart M. (2000) Growing Alike or Growing Apart? Industrial Specialization of EU Countries, mimeo.

Chiarlone S. (2002) Country specialization and trade overlap: whom are the central-eastern european countries competing with?, in: EU enlargement to the CEECs: trade competition, delocalization of production and effects on the economies of the Union, Baldone S., Sdogati F. and L.Tajoli, eds., Franco Angeli Editore, Milano.

Clark T. and van Wincoop E. (2000) Borders and business cycles, Journal of International Economics, 55, 59-85.

Deardorff A.V. (1994) The possibility of factor price equalization revisited, Journal of International Economics, 36, 1-2, 176-175.

European Council (1993) Conclusions of the Presidency, Copenhagen, $\mathrm{DOC} / 93 / 3$.

Freudenberg M. and Lemoine F. (1999) Central and Eastern European countries in the international division of labour in Europe, CEPII Document de travail .

Halpern L. (1995) Comparative advantage and likely trade pattern of the CEECs, in: European Union Trade with Eastern Europe, Faini R. and Portes R., eds., CEPR, London, 61-85.

Imbs J. (2001) Co-Fluctuations, CEPR Discussion Paper n. 2267. 
Kaminski B. (2001) How accession to the European Union has affected external trade and foreign direct investment in Central European Economies, World Bank Working Paper n.2578.

Krugman P. (1981) Intraindustry specialization and the gains from trade, Journal of Political Economy, 89, 5.

Krugman P. (1991) Geography and Trade, The MIT Press, New York.

Krugman P. (1993) Lessons of Massachussets for EMU, in: Adjustment and Growth in the European Monetary Union, Torres F. and Giavazzi F., eds., Cambridge University Press, Cambridge.

Landesmann M. (1996) Emerging patterns of European specialization: implications for labour market dynamics in Eastern and Western Europe, wIIW working paper n. 230.

Landesmann M. (2003) Structural features of economic integration in an Enlarged Europe: patterns of catching-up and industrial specialisation, european Commission Directorate-general for Economic and Financial Affairs Economic Paper n. 181.

Landesmann M. and Stehrer (2002) Evolving competitiveness of CEECs in an Enlarged Europe, Rivista di Politica Economica, 92, 1-2, 23-87.

Legendre P. and Legendre L. (1998) Numerical Ecology, Elsevier, 2nd edition.

Menon J. and Dixon P. (1997) Intraindustry v.s. Interindustry Trade: Relevance for Adjustment Costs, Weltwirtshaftliches Archiv, 133, 1, 164-169.

Neven D. (1995) Trade liberalization with eastern nations: how sensitive?, in: European Union trade with Eastern Europe: adjustment and opportunities, Faini R. and Portes R., eds., CEPR, London, 19-60.

Nuti D.M. (2001) Not "just an other accession", Leon Kozminski Academy of Entrepreneurship and Management, Warsaw, Distinguished Lectures Series n. 3.

Redding S. (2001) The Dynamics of International Specialization, Journal of International Economics.

Tajoli L. (1998) The economic integration between the European Union and the CEECs: can we learn from the past?, quaderno DEP n.31.

Wang Z. and Winters A. (1994) Eastern Europe's International Trade, Manchester University Press, Manchester. 
Figure 1: CEECs Exports towards EU: Total and Final Exports
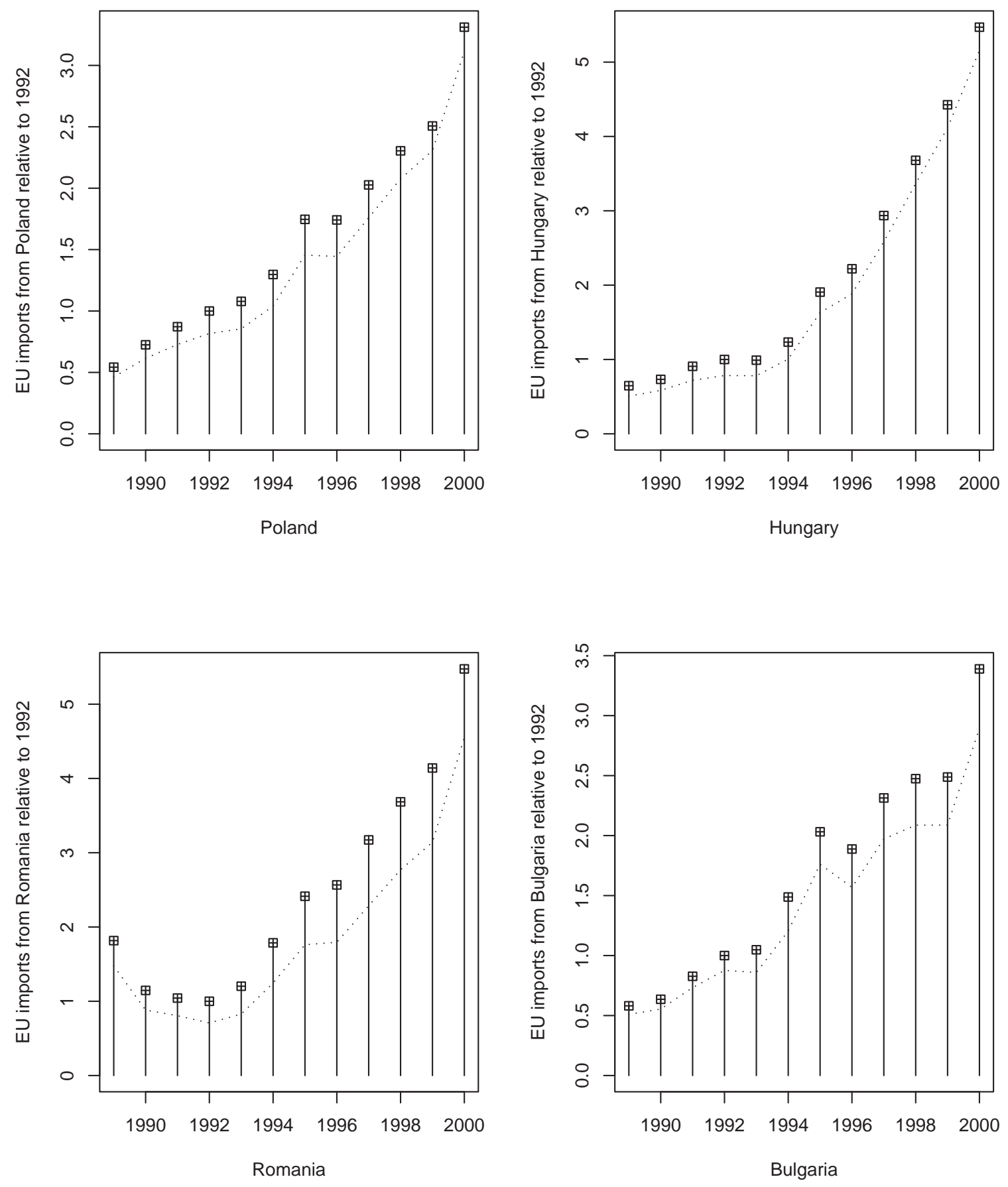
Figure 2: Total Export Shares Dynamics 1989-2000

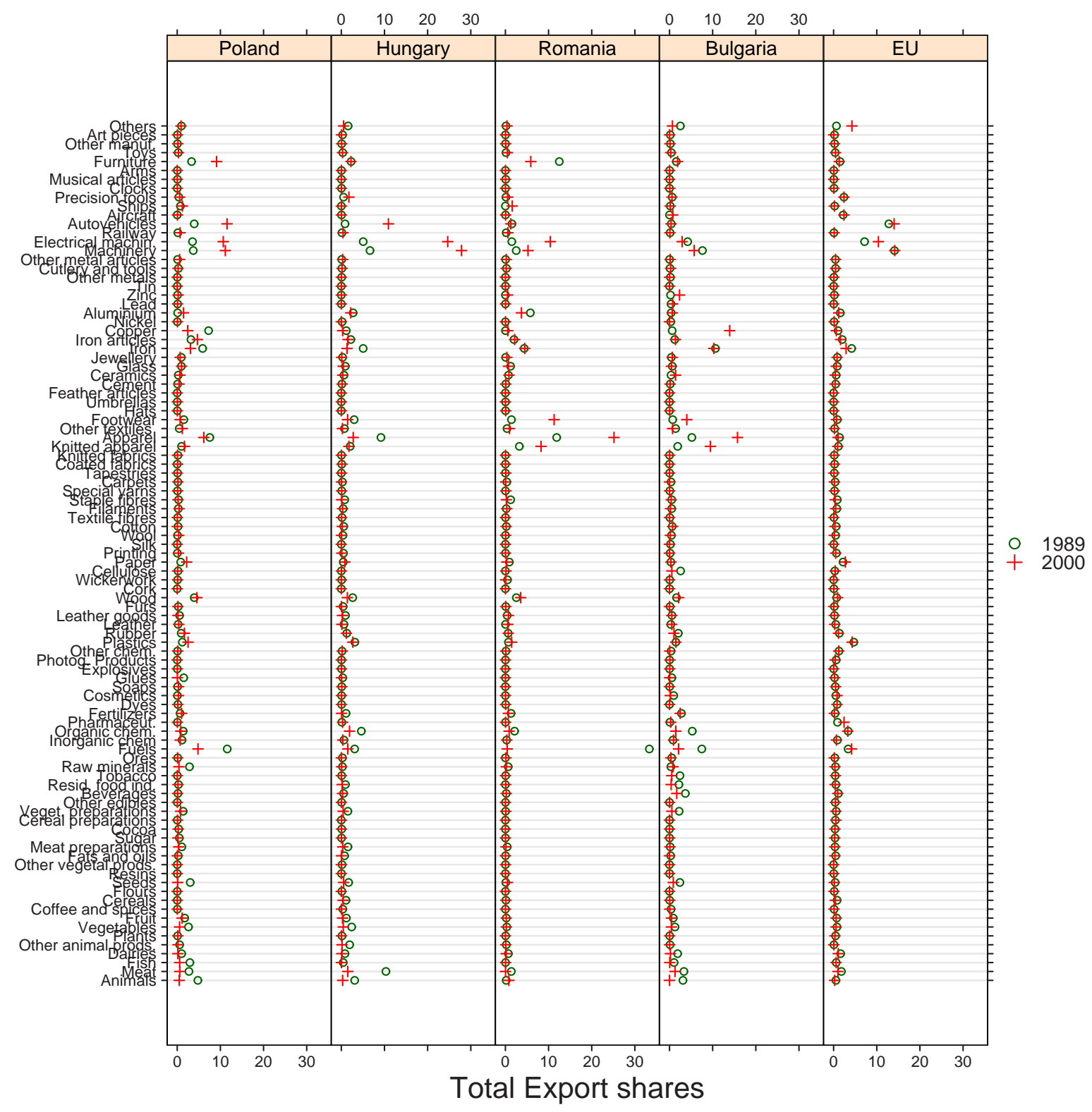


Figure 3: Processed Export Shares Dynamics 1989-2000

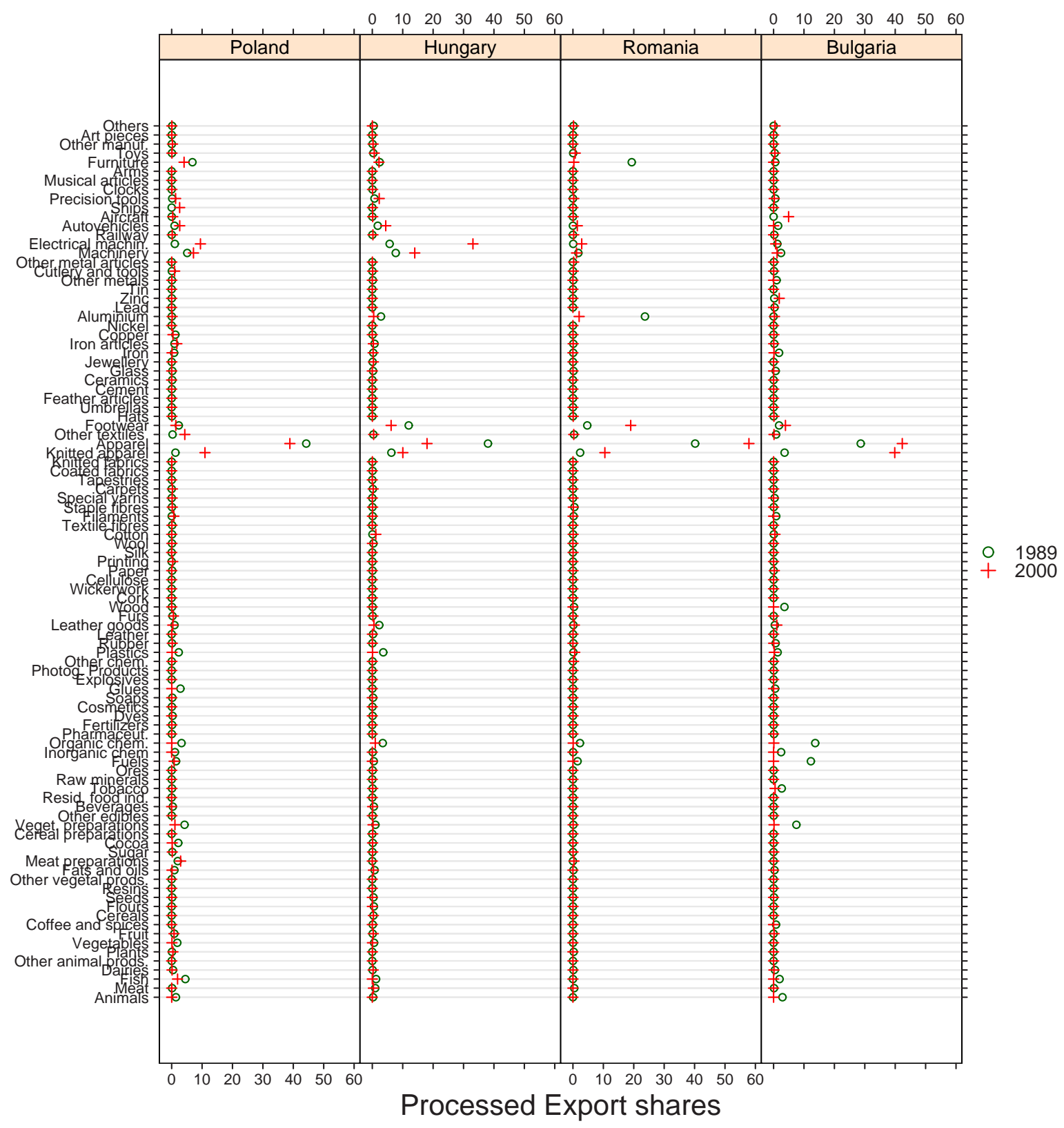


Figure 4: Tukey's boxplots of CEECs Total Exports towards EU
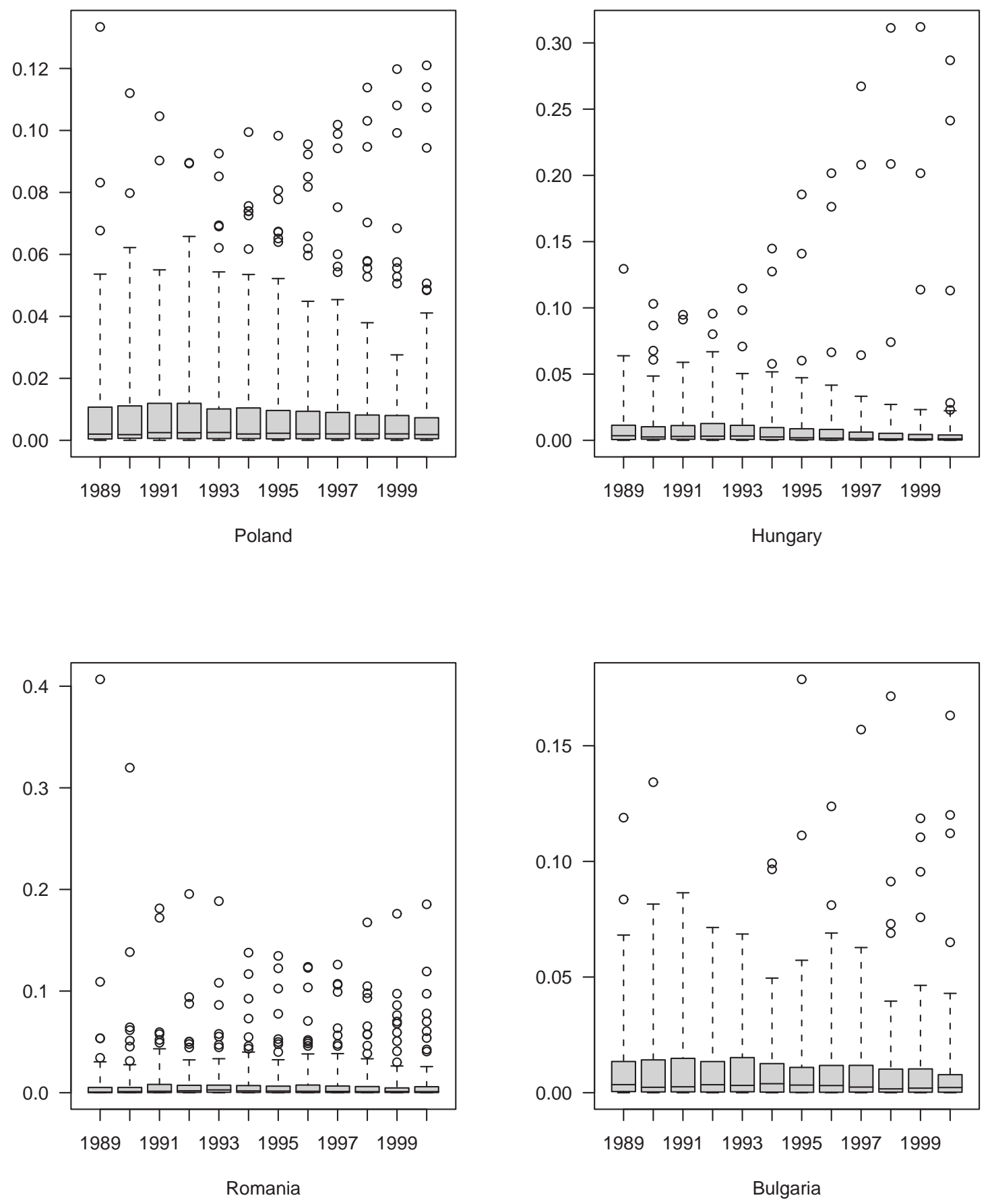
Figure 5: Poland - distance dynamics
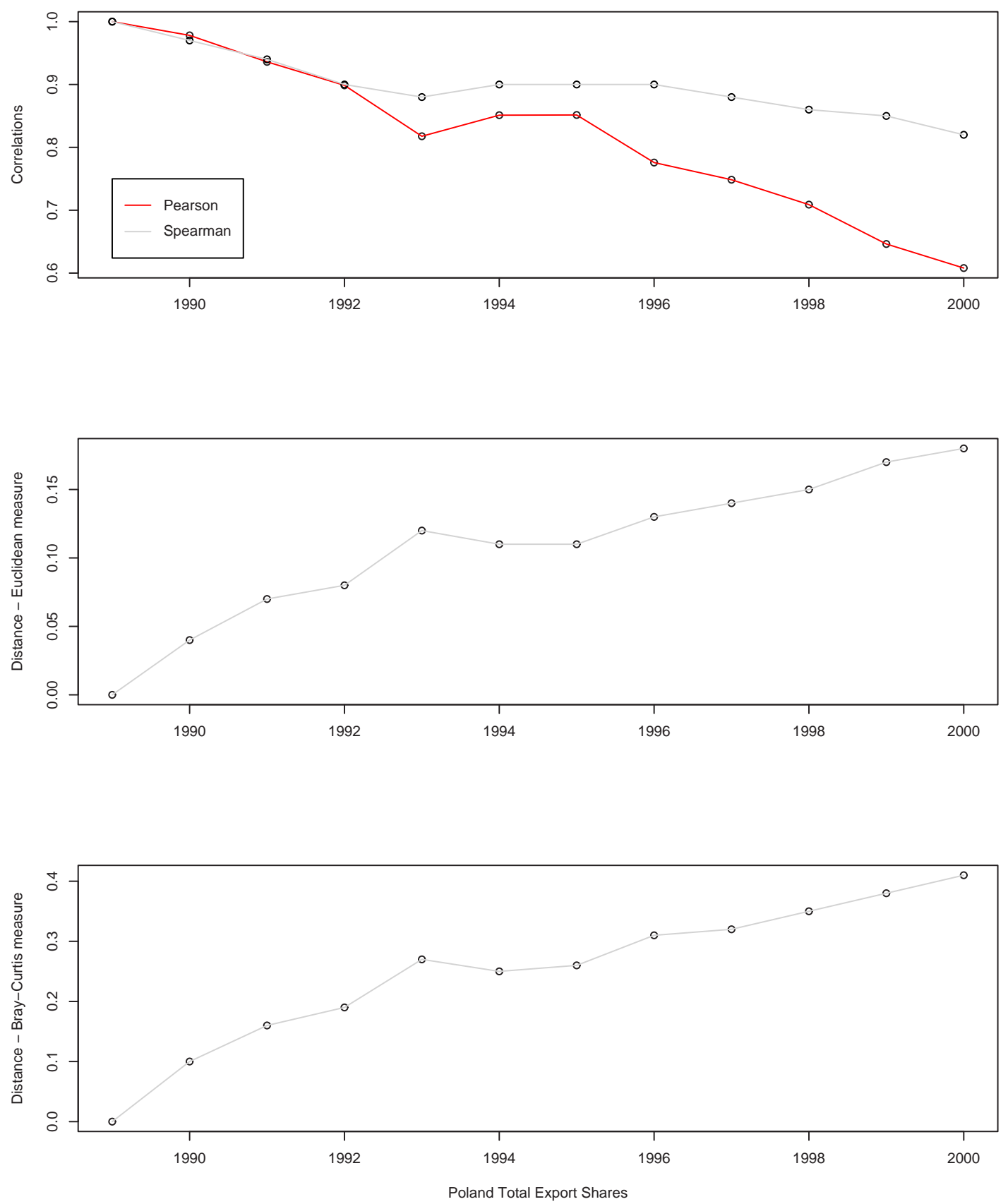
Figure 6: Hungary - distance dynamics
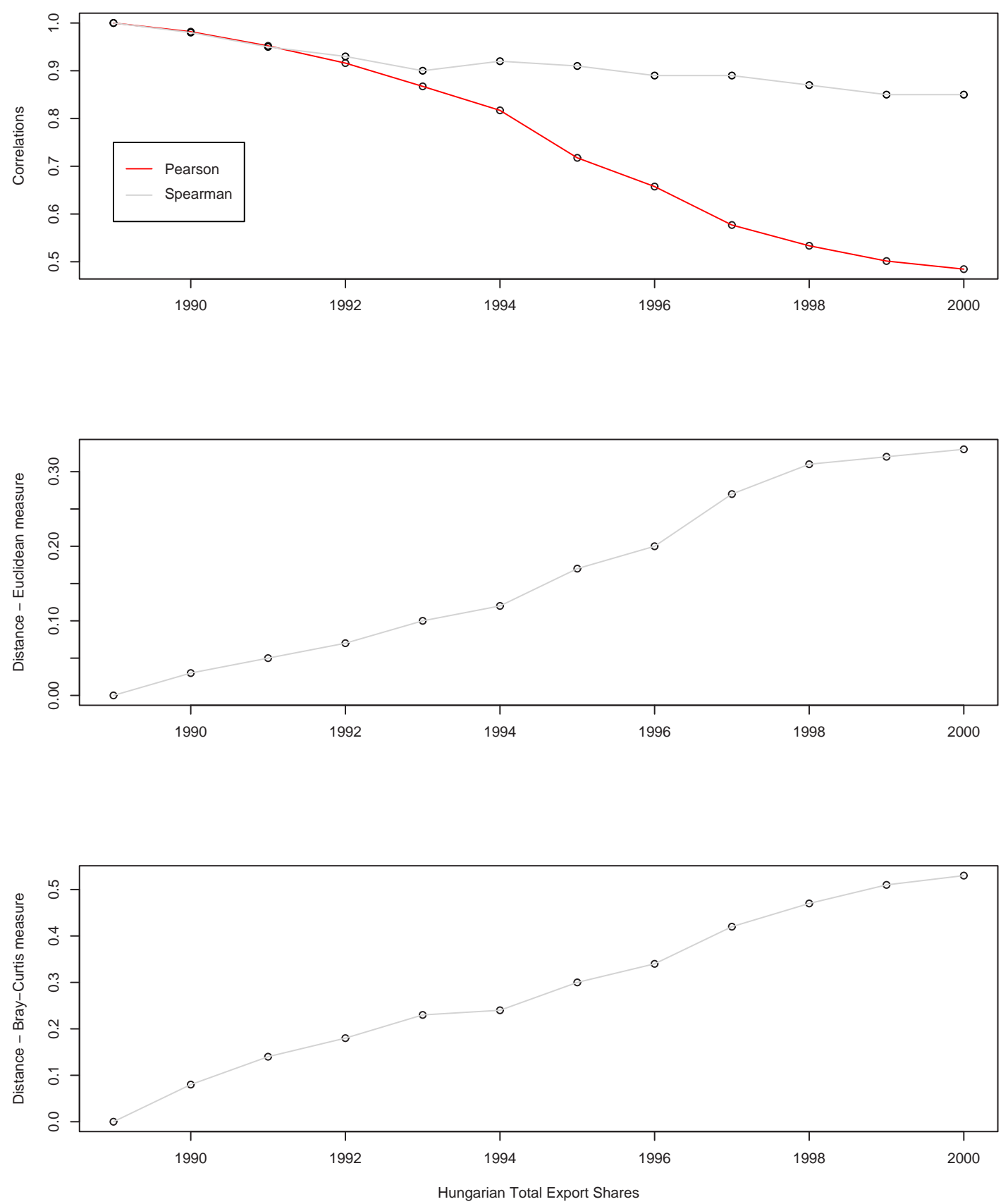
Figure 7: Romania - distance dynamics
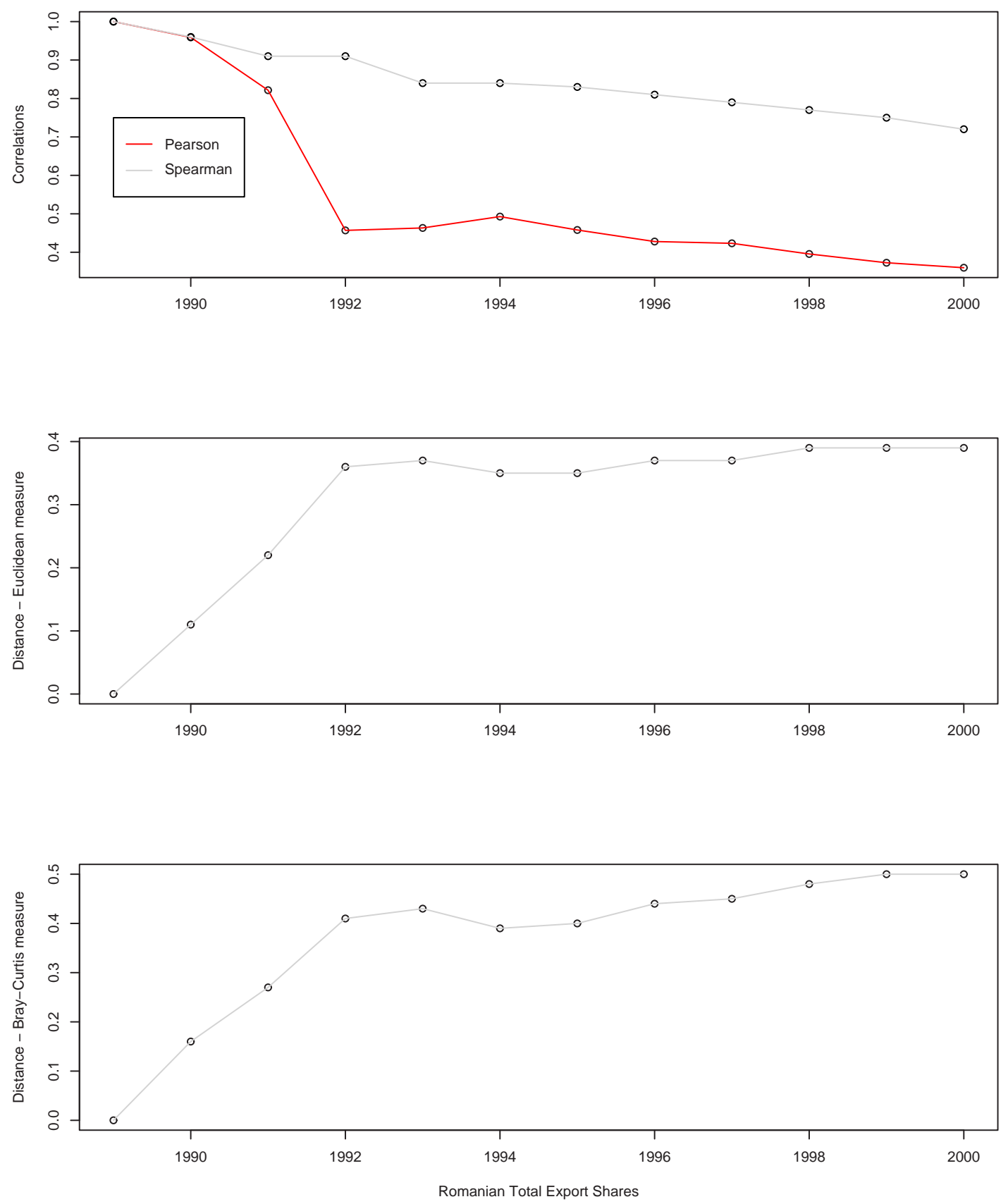
Figure 8: Bulgaria - distance dynamics
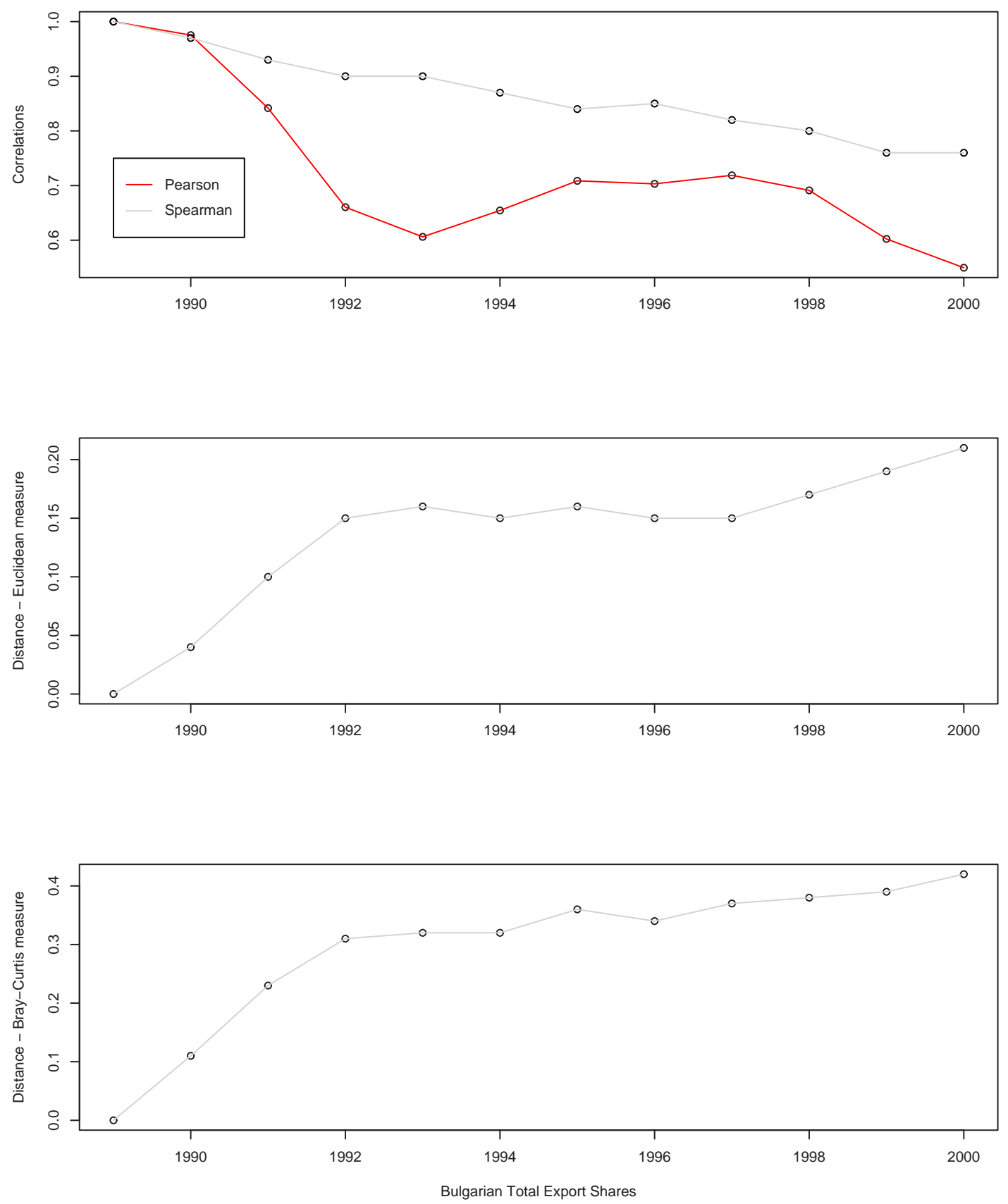
Figure 9: EU - distance dynamics
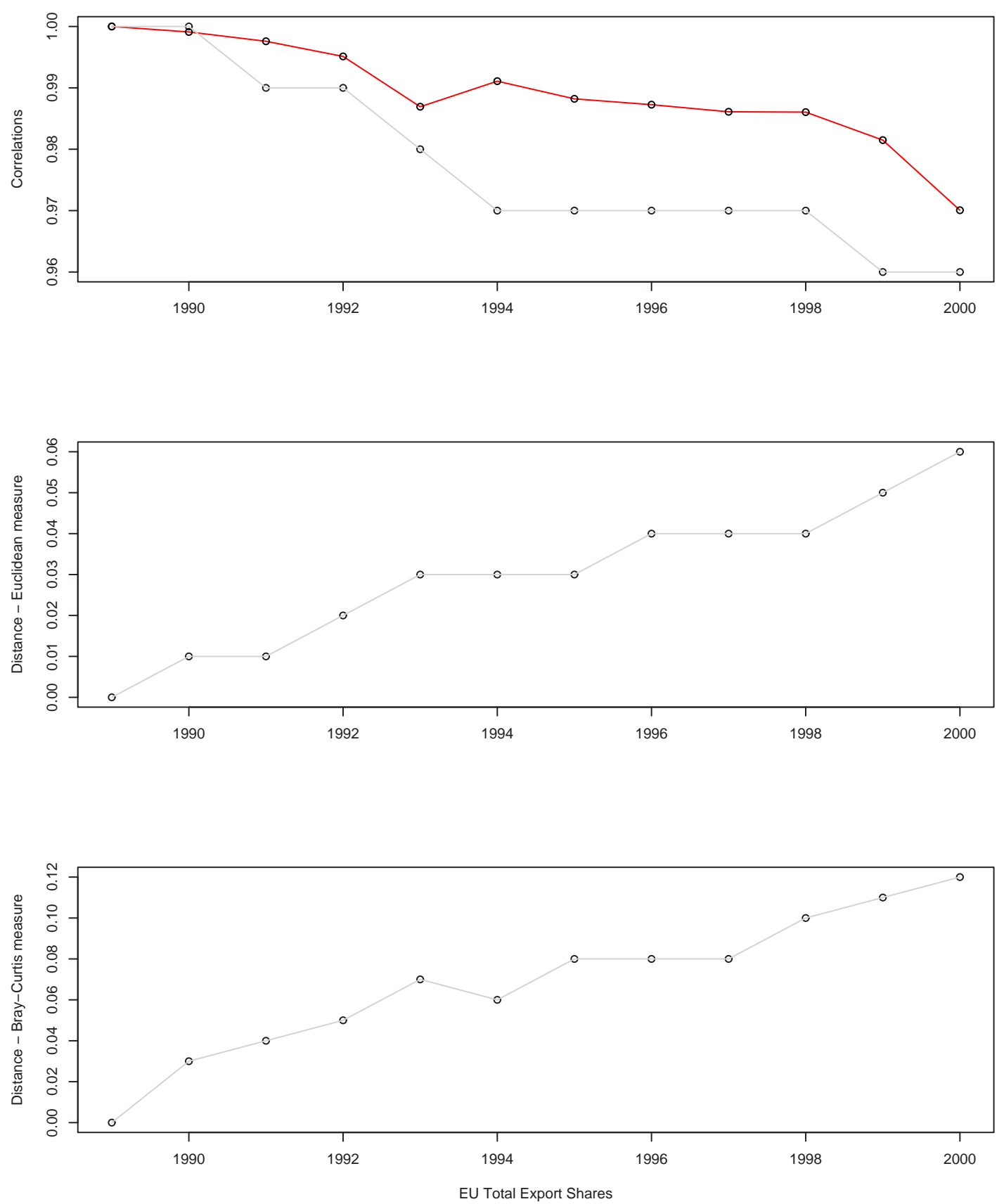
Figure 10: Poland EU - similarities
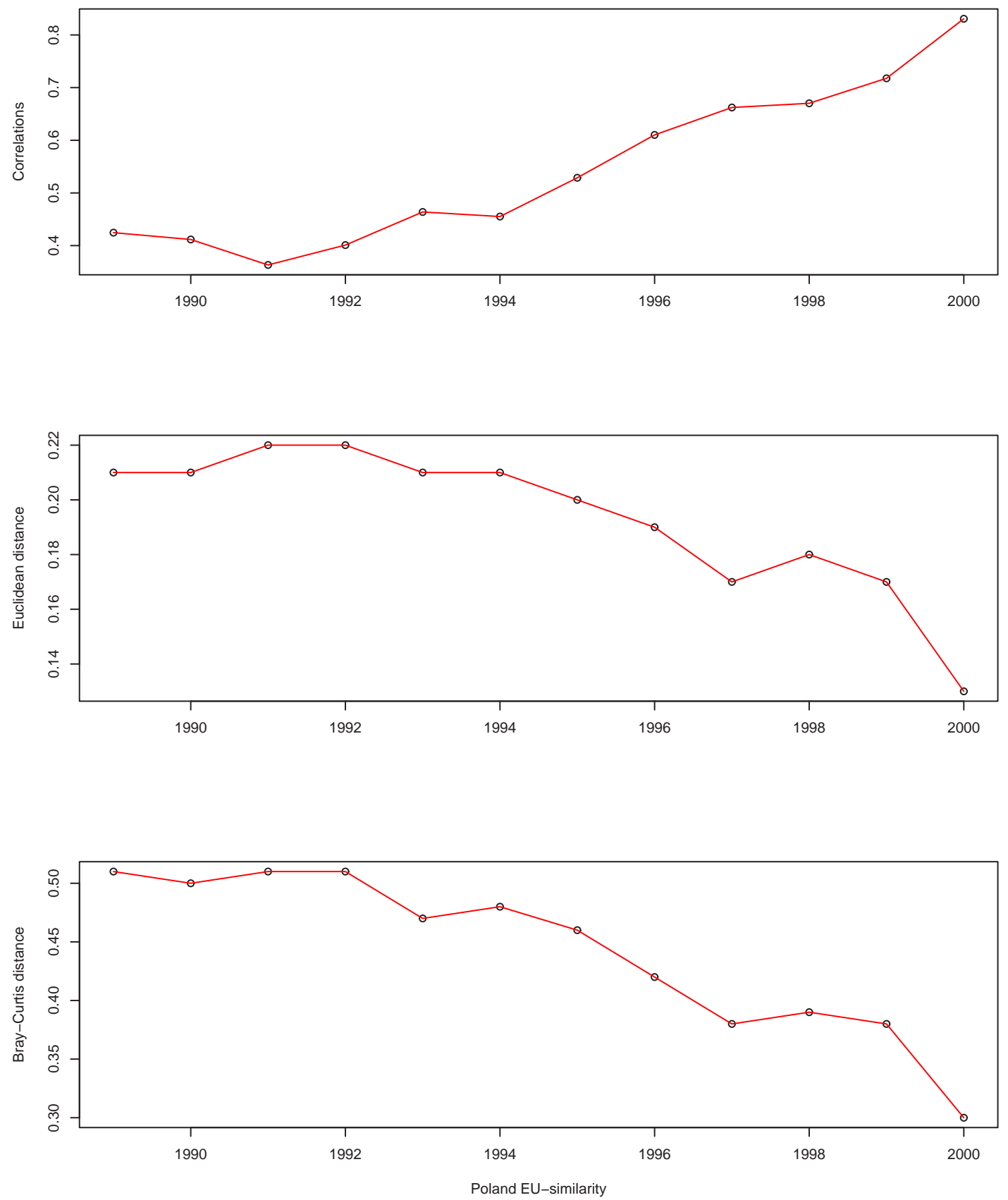
Figure 11: Hungary EU - similarities
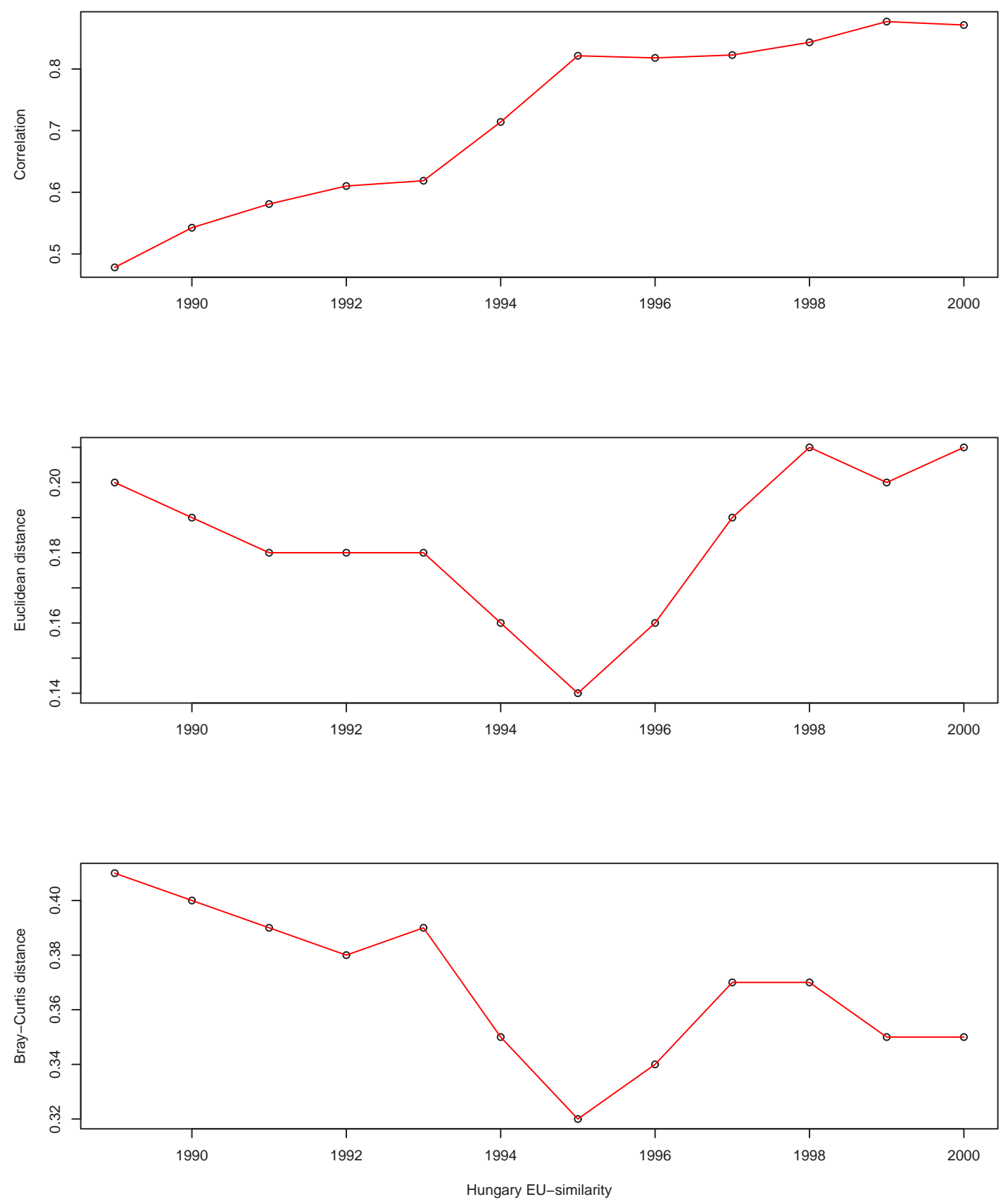
Figure 12: Romania EU - similarities
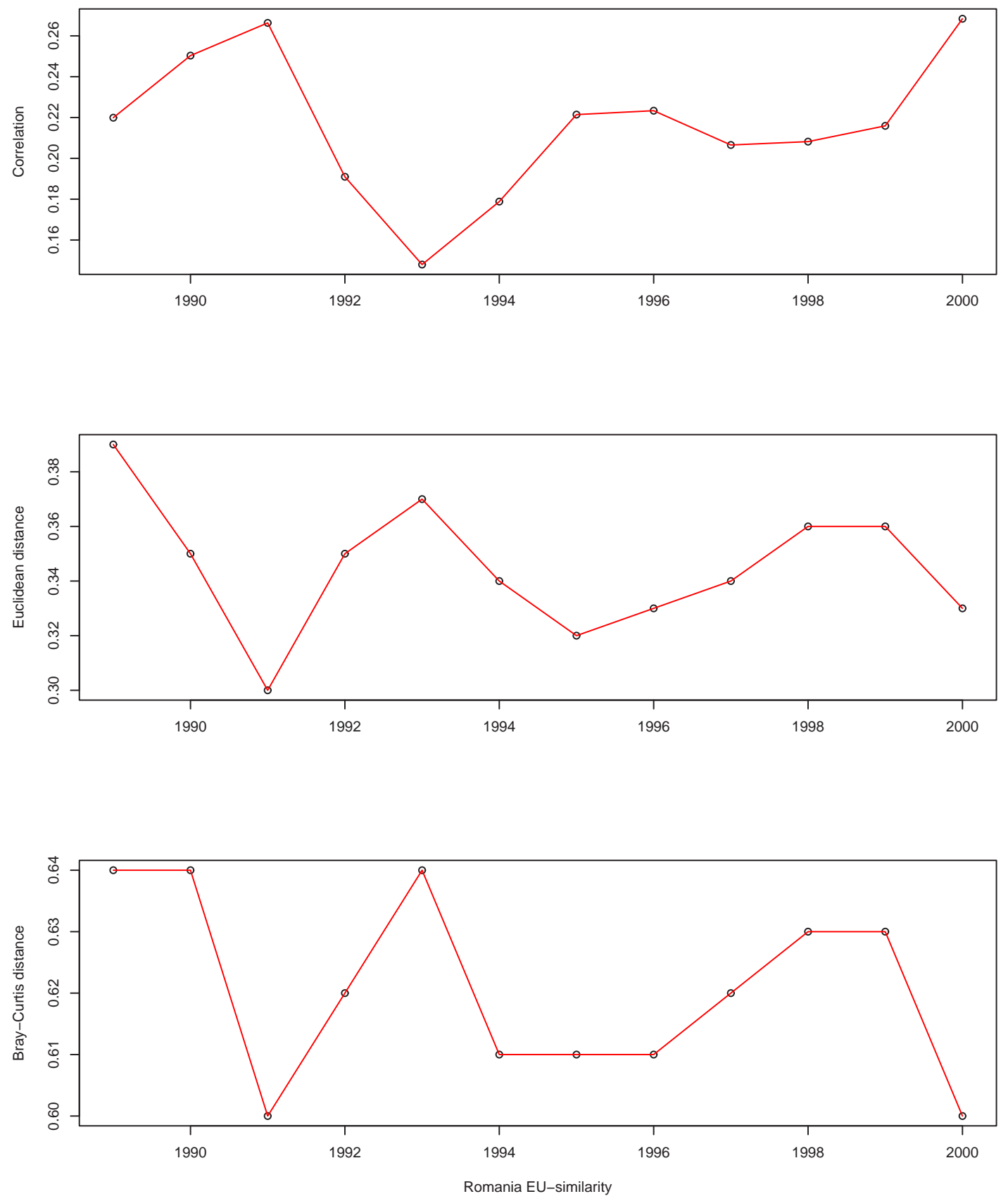
Figure 13: Bulgaria EU - similarities
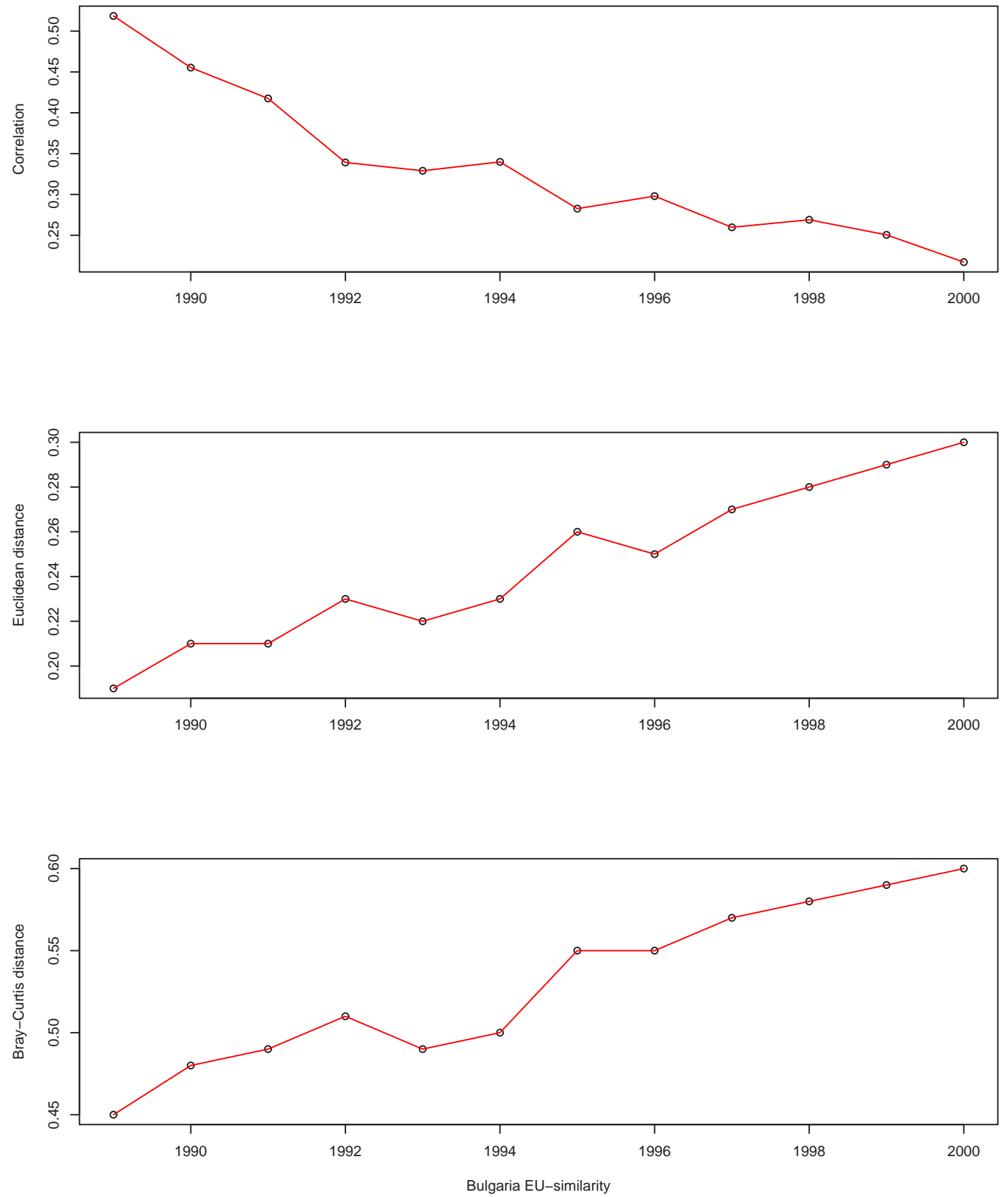
Figure 14: Self and EU similarities

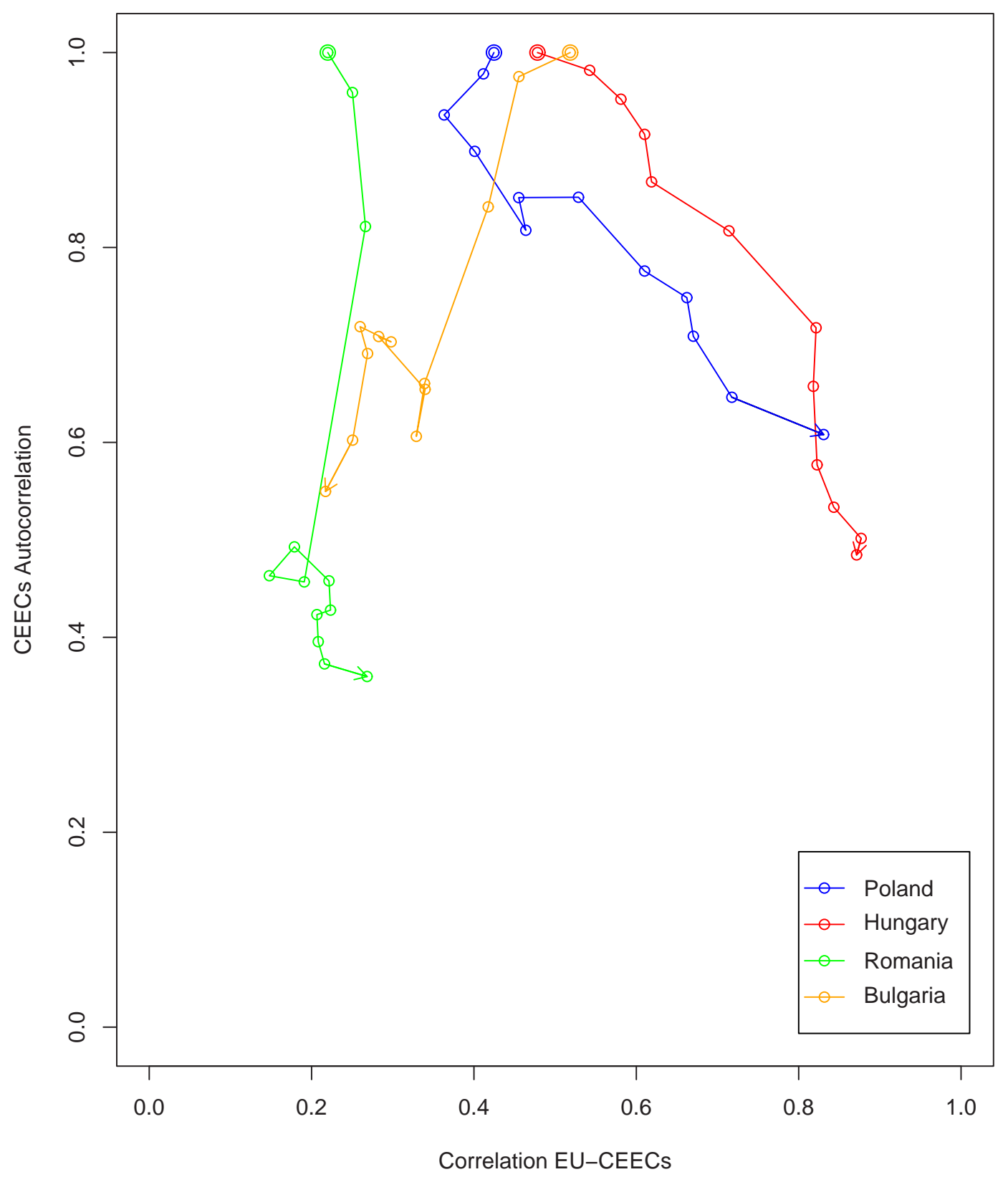


Figure 15: Self and EU similarities

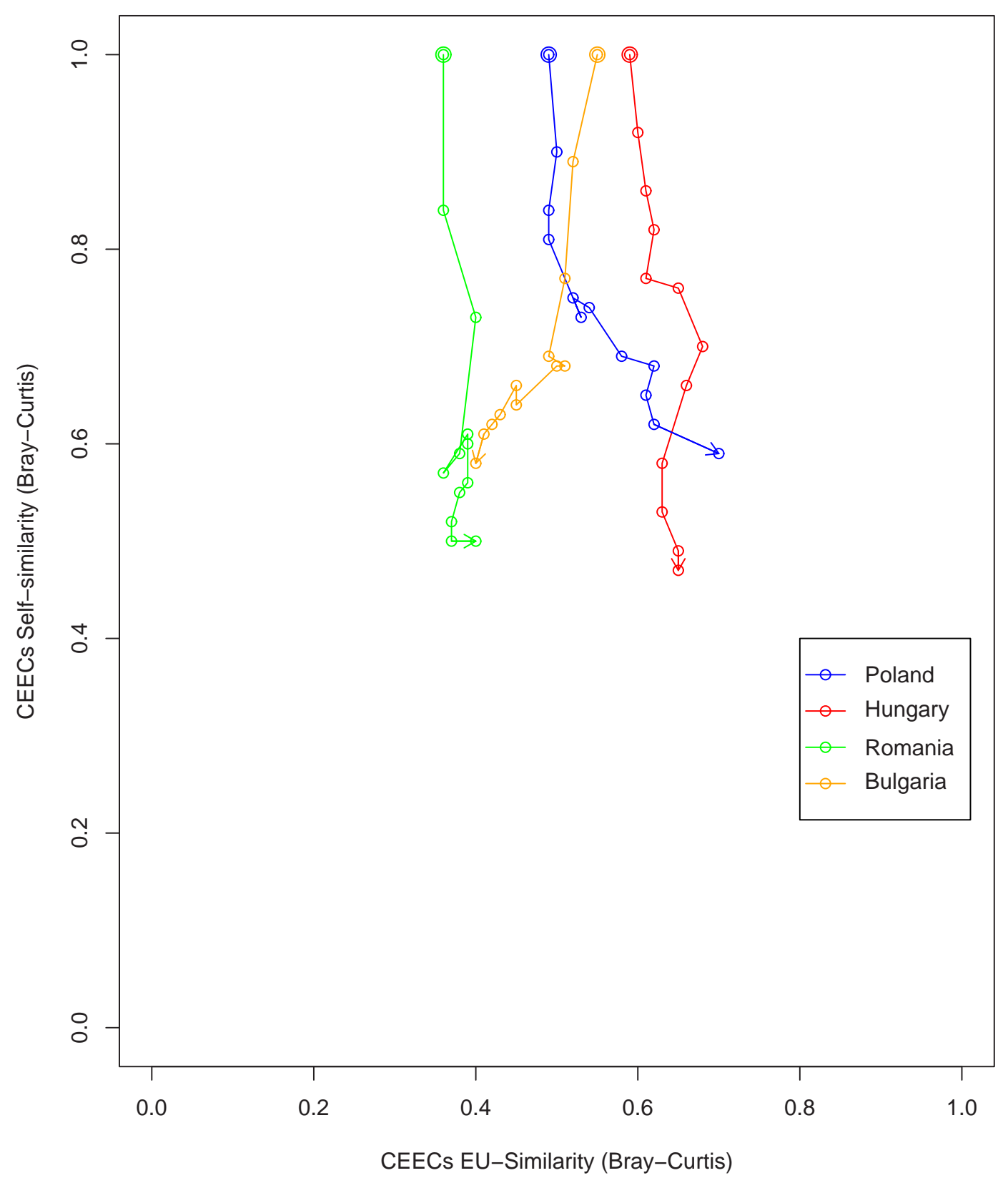

